\title{
Global distribution of $\mathrm{CO}_{2}$ in the upper troposphere and stratosphere
}

\author{
Mohamadou Diallo ${ }^{1,2,7}$, Bernard Legras ${ }^{1}$, Eric Ray ${ }^{3,4}$, Andreas Engel ${ }^{5}$, and Juan A. Añel ${ }^{2,6}$ \\ ${ }^{1}$ Laboratoire de Météorologie Dynamique, UMR8539, IPSL, CNRS/ENS/UPMC/Ecole Polytechnique, Paris, France \\ ${ }^{2}$ EPhysLab, Facultade de ciencias, Universidade de Vigo, Ourense, Spain \\ ${ }^{3}$ Chemical Sciences Division, Earth Systems Research Laboratory, NOAA, Boulder, Colorado, USA \\ ${ }^{4}$ Cooperative Institute for Research in Environmental Sciences, University of Colorado, Boulder, Colorado, USA \\ ${ }^{5}$ Institute for Atmospheric and Environmental Sciences, Goethe University Frankfurt, Frankfurt am Main, Germany \\ ${ }^{6}$ Smith School of Enterprise and the Environment, University of Oxford, Oxford, UK \\ ${ }^{7}$ Institute for Energy and Climate Research - Stratosphere (IEK-7), Forschungszentrum Jülich, Jülich, Germany \\ Correspondence to: Mohamadou Diallo (m.diallo@fz-juelich.de)
}

Received: 6 May 2016 - Discussion started: 6 June 2016

Revised: 3 February 2017 - Accepted: 21 February 2017 - Published: 21 March 2017

\begin{abstract}
In this study, we construct a new monthly zonal mean carbon dioxide $\left(\mathrm{CO}_{2}\right)$ distribution from the upper troposphere to the stratosphere over the 2000-2010 time period. This reconstructed $\mathrm{CO}_{2}$ product is based on a Lagrangian backward trajectory model driven by ERA-Interim reanalysis meteorology and tropospheric $\mathrm{CO}_{2}$ measurements. Comparisons of our $\mathrm{CO}_{2}$ product to extratropical in situ measurements from aircraft transects and balloon profiles show remarkably good agreement. The main features of the $\mathrm{CO}_{2}$ distribution include (1) relatively large mixing ratios in the tropical stratosphere; (2) seasonal variability in the extratropics, with relatively high mixing ratios in the summer and autumn hemisphere in the $15-20 \mathrm{~km}$ altitude layer; and (3) decreasing mixing ratios with increasing altitude from the upper troposphere to the middle stratosphere $(\sim 35 \mathrm{~km})$. These features are consistent with expected variability due to the transport of long-lived trace gases by the stratospheric Brewer-Dobson circulation. The method used here to construct this $\mathrm{CO}_{2}$ product is unique from other modelling efforts and should be useful for model and satellite validation in the upper troposphere and stratosphere as a prior for inversion modelling and to analyse features of stratospheretroposphere exchange as well as the stratospheric circulation and its variability.
\end{abstract}

\section{Introduction}

The global stratospheric meridional circulation, also called the Brewer-Dobson circulation (BDC), was recognized as a major component of the climate system, which affects radiative forcing (Lacis et al., 1990; Forster and Shine, 1997; Forster et al., 2007) and atmospheric circulation (Andrews et al., 1987; Holton et al., 1995; Salby and Callaghan, 2005, 2006). The increase in greenhouse gases, in particular the carbon dioxide $\left(\mathrm{CO}_{2}\right)$ concentration, affects the atmospheric temperature and wave propagation, which increases the tropical upwelling mass flux (Butchart et al., 2010; Garny et al., 2011; Abalos et al., 2015) and therefore changes the BDC. Within the context of climate change, the stratospheric circulation variability can also be diagnosed using the trace gas $\mathrm{CO}_{2}$.

$\mathrm{CO}_{2}$ is a useful tracer of atmospheric dynamics and transport because of its long lifetime in the troposphere and stratosphere, where it has essentially no sources or sinks since it is basically chemically inert in the free troposphere. The only stratospheric source of $\mathrm{CO}_{2}$ is a small contribution from methane oxidation that can reach up to $1 \mathrm{ppmv}$ (i.e. parts per million per volume) (Boucher et al., 2009). $\mathrm{CO}_{2}$ is regularly exchanged between four reservoirs: the biosphere (photosynthesis and respiration), the lithosphere (soil and fossil pool), the hydrosphere (surface and deep ocean), and the atmosphere, with a much longer residence time in the oceans 
and soil than in the atmosphere. These exchanges are described as the carbon cycle. Anthropogenic emissions due primarily to deforestation and biomass and fossil fuel burning have systematically increased the mean $\mathrm{CO}_{2}$ and modified its seasonal cycle during these last 2 decades (Tans and Keeling, 2015). With the influences of steady growth and seasonal variation, $\mathrm{CO}_{2}$ concentrations in the atmosphere contain both monotonically increasing and periodic signals that represent stringent tests of stratospheric transport and stratosphere-troposphere exchange (STE) in models (Waugh and Hall, 2002; Bönisch et al., 2008, 2009).

Despite its potential to increase global change by cooling the stratosphere and warming the troposphere via the greenhouse effect, information on stratospheric $\mathrm{CO}_{2}$ and its variability was sparse until recently. In recent years, in situ aircraft and balloon campaigns were implemented in order to measure a number of chemical tracers, including $\mathrm{CO}_{2}$. The in situ campaigns included SPURT aircraft measurements in the upper troposphere and lower stratosphere (UTLS) (Engel et al., 2006; Gurk et al., 2008), CONTRAIL (Sawa et al., 2008), and CARIBIC (Schuck et al., 2009; Sprung and Zahn, 2010). Although sporadic in time and space coverage, these in situ measurements were used to analyse the BDC changes (Andrews et al., 2001a; Engel et al., 2009; Ray et al., 2014), to validate chemistry-transport models (CTMs) (Strahan et al., 2007; Waugh, 2009), and to diagnose STE (Strahan et al., 1998; Hegglin et al., 2005; Hoor et al., 2005, 2010; Bönisch et al., 2009, 2011).

The stratospheric overworld circulation changes that affect the extratropical UTLS were recently assessed by Engel et al. (2009) from balloon-based measurements of $\mathrm{SF}_{6}$ (sulfur hexafluoride) and $\mathrm{CO}_{2}$. The stratospheric mean age of the air, which is defined as the residence time of air parcels in the stratosphere ( $\mathrm{Li}$ and Waugh, 1999; Waugh and Hall, 2002; Butchart et al., 2010), was calculated by Ray et al. (2014) from the in situ balloon measurements of trace gases, with an idealized model to identify the natural variability in the BDC and its significant linear trends. This study demonstrated the importance of reconstructed in situ measurements to validate the stratospheric representation in global CTMs and chemistry-climate models (CCMs).

In addition to the very localized in situ observations, which have high spatial resolution, a large spatial and temporal coverage of $\mathrm{CO}_{2}$ is obtained from space instruments such as the vertical nadir sounders TOVS (Chedin et al., 2002, 2003b), AIRS (Chedin et al., 2003a), SCIAMACHY (Bowman et al., 2000), IASI (Chedin et al., 2003a), GOSAT (Hammerling et al., 2012; Liu et al., 2014), and recently OCO-2 (Frankenberg et al., 2015). These spaceborne instruments essentially measure total column $\mathrm{CO}_{2}$, weighted more by the lower and mid-troposphere; hence, they provide limited information on the upper troposphere and the stratosphere. Foucher et al. $(2009,2011)$ obtained 5 years of monthly mean $\mathrm{CO}_{2}$ vertical profiles by analysing the ACE-FTS data (Bernath et al., 2005). The ACE-retrieved $\mathrm{CO}_{2}$ shows qualitatively good agreement with in situ observations for the 2004-2008 time period at the $50-60^{\circ} \mathrm{N}$ latitude bins. However, the retrieval sensitivity is limited and averages need to be performed on a large number of profiles.

Because of the limited observations, CTMs and Lagrangian transport models are a complementary and useful framework for widely diagnosing the BDC and representing the global transport and distribution of long-lived species, such as $\mathrm{CO}_{2}$.

Previous studies using the two-dimensional CTM Caltech/JPL (Shia et al., 2006) and the three-dimensional CTM TM5 (Transport Model 5) (Bönisch et al., 2008) were unable to accurately represent the BDC. Bönisch et al. (2008) investigated the UTLS exchanges in a three-dimensional transport model using the observed $\mathrm{CO}_{2}$ and $\mathrm{SF}_{6}$ distributions and concluded that major disagreements between the model and observations occur in winter, where a too-strong BDC leads to some overestimates of the $\mathrm{CO}_{2}$, and in boreal summer, where the vertical transport is too slow in the upper troposphere. During autumn the models showed an unrealistic persistent reverse gradient in the lower stratosphere, and during spring the transport processes through the tropical tropopause were overestimated, inducing too-high $\mathrm{CO}_{2}$ values in the lower stratosphere. Furthermore, many threedimensional models are too diffusive and/or have too-strong mixing when crossing the tropopause, which leads to an underestimation of the amplitude of the seasonal cycle in the column of $\mathrm{CO}_{2}$ (Olsen and Randerson, 2004). Shia et al. (2006) suggested that the lack of a reliable representation of stratospheric influence on $\mathrm{CO}_{2}$, e.g. intrusion and recirculation, could explain part of the discrepancy between a CTM and observations. The persistence of the inverted $\mathrm{CO}_{2}$ gradient noted in these models can result in an underestimation of the exchange of air masses from the stratosphere to the troposphere in mid-latitudes during autumn. Due to the short time period of simulations, models also fail to calculate a reliable $\mathrm{CO}_{2}$ seasonal cycle as well as STE. Shia et al. (2006) concluded that at least 3 years are required for the surface $\mathrm{CO}_{2}$ to be transported into the upper troposphere and lowermost stratosphere (LMS) then moved to the temperate and polar latitudes. In order to eliminate the spurious diffusivity effect, Lagrangian or quasi-Lagrangian models, such as TRACZILLA (Legras et al., 2005) and CLaMS (Chemical Lagrangian Model of the Stratosphere) (Pommrich et al., 2014), were widely used to investigate transport properties. The combination of these Lagrangian models with in situ observations to reconstruct chemical trace gas distributions has significantly contributed to our understanding of the mixing effects across the extratropical tropopause (Hoor et al., 2004; Pan et al., 2006; James and Legras, 2009), the filamentary structure in long-lived and short-lived species near the edge of the polar vortex (Konopka et al., 2003), the transport of long-lived species and $\mathrm{CO}$ from the tropical troposphere to the stratosphere (Pommrich et al., 2014), and the processes that control UTLS composition (Riese et al., 2012). 
The small-scale variability of $\mathrm{CO}_{2}$, its strong gradients across the tropopause, and the scarcity of suitable observations for validation purposes lead to a challenging task for CTMs and CCMs in reconstructing its distribution in the UTLS (Hegglin et al., 2008).

In this paper, our goal is to build a database of the monthly zonal mean distribution of $\mathrm{CO}_{2}$ on a global scale extending from the upper troposphere to the stratosphere using backward Lagrangian trajectories. This product can be used to validate CTMs; CCMs, as a prior for inversion modelling; and to analyse features of the STE as well as the stratospheric circulation and its variability.

The trajectory data set on which this work is based was used by Diallo et al. (2012) to study the age of air and its variability in the stratosphere. We refer to this previous work for all related questions. The present study can also be seen as a further validation of Diallo et al. (2012).

We reconstruct a global distribution of $\mathrm{CO}_{2}$ calculated over the time period 2000-2010 from a Lagrangian transport model driven by horizontal winds and diabatic heating rates, representing the vertical velocity in the isentropic coordinate, from the ERA-Interim reanalysis provided by the European Centre for Medium Range Weather Forecast (ECMWF) (Dee et al., 2011). We describe the data and method used in this study in Sects. 2 and 3, respectively. The reconstructed $\mathrm{CO}_{2}$ is compared with observations in Sect. 4. The global monthly distribution of the zonal mean $\mathrm{CO}_{2}$ and its variability are discussed in Sect. 5. Finally, Sect. 6 provides further discussions and conclusions.

\section{Data}

The reconstruction of the global distribution of $\mathrm{CO}_{2}$ from the upper troposphere to the stratosphere through the use of back trajectories requires the value of the $\mathrm{CO}_{2}$ mixing ratio to be assigned at the lower tropospheric boundary. This is achieved by using two different types of $\mathrm{CO}_{2}$ data: ground stations (Worden et al., 2015) and CarbonTracker (Peters et al., 2007). In addition, in situ measurements of $\mathrm{CO}_{2}$ from balloons and aircraft were used to validate the reliability of the model reconstructions (Daube et al., 2002; Engel et al., 2009; Sawa et al., 2008).

\subsection{Lower boundary condition of the backward trajectories}

Two different observation-based data sets are used to assign $\mathrm{CO}_{2}$ to air parcels transported along the backward trajectories. During the 1989-1999 time period, data from ground stations of the World Data Centre for Greenhouse Gases (WDCGG, http://ds.data.jma.go.jp/gmd/wdcgg/) are applied. The WDCGG is an international data centre participating in the WMO Global Atmosphere Watch. It provides extensive data from ground stations and aircraft measurements across the Earth that are non-homogeneously distributed. The monthly $\mathrm{CO}_{2}$ data from ground stations (e.g. Mauna Loa, South Pole, and others) located at different latitudes were used to overcome the daily fluctuations of $\mathrm{CO}_{2}$ in the atmospheric boundary layer. The criterion for selecting the ground stations is that they are remotely located with respect to localized anthropogenic sources. In highly industrialized regions, this criteria is performed by retaining only high-altitude stations to neglect the variability from localized sources at ground level. The $\mathrm{CO}_{2}$ data are averaged from pole to pole in latitude increments of $30^{\circ}$ and over all longitudes to represent the global, free tropospheric $\mathrm{CO}_{2}$ field. To better model the latitude dependence of the seasonal cycle and to overcome discontinuities, the averaged $\mathrm{CO}_{2}$ data obtained are then interpolated linearly in latitude. Since the ground station locations are inadequate to define longitudinal variability, we use a constant $\mathrm{CO}_{2}$ value at all longitudes for each latitude bin. According to CarbonTracker residuals against the NOAA North American aircraft network data at altitudes above the planetary boundary layer (PBL) (http://www.esrl.noaa. gov/gmd/ccgg/carbontracker/profiles.php), the mean error of CarbonTracker is less than $1.25 \mathrm{ppmv}$ at $500 \mathrm{hPa}$. This error should be added, in mean square, to the error determined in this study as a result of model dispersion (Sect. 5.3).

For the 2000-2010 time period, we use $\mathrm{CO}_{2}$ output from the coupled data assimilation system CarbonTracker with the TM5 transport model for the lower boundary condition (Huijnen et al., 2010). CarbonTracker produces full 3-D dimensional output so that the backward trajectories are assigned to daily $\mathrm{CO}_{2}$ mole fractions based on the latitude and longitude $\left(3^{\circ} \times 2^{\circ}\right.$ resolution) of the trajectory at the $5 \mathrm{~km}(500 \mathrm{hPa})$ level. The $5 \mathrm{~km}$ level was chosen to represent the well-mixed free troposphere. The CarbonTracker system assimilates $\mathrm{CO}_{2}$ observations from atmospheric stations and optimizes underlying $\mathrm{CO}_{2}$ mixing ratio from the fluxes of the ocean, biosphere, biomass burning and fossil fuel usage. These data are meant to achieve a complete and realistic diagnostic of the lower-atmospheric $\mathrm{CO}_{2}$ and fluxes (CarbonTracker-2013B, www.esrl.noaa.gov/gmd/ ccgg/carbontracker/). The version used in this study corrects an error in vertical mixing in the previous versions.

Admittedly, the reduced sampling of the pre-2000 period and the lack of zonal variability induces an increased uncertainty in our calculation. However, the zonal variability is largely filtered out in the upper troposphere and lower stratosphere, especially during winter. Moreover, we only provide $\mathrm{CO}_{2}$ reconstructions for 2000-2010. During this period, the tropospheric conditions are mostly determined by CarbonTracker output due to the fast transport time in the troposphere, and the zonal fluctuations are mostly washed out in the stratosphere. The influence of pre-2000 data then decays exponentially and almost vanishes after 2005 . 


\subsection{In situ aircraft and balloon measurements}

In the UTLS, there are strong horizontal and vertical gradients. These gradients may occur on a small scale and exhibit high temporal and spatial variability. In this study, we are interested in airborne measurements in order to validate our model as well as to characterize the stratospheric variability and mixing process. Aircraft observations have a vertical resolution of a few metres (during ascents and descents) and a horizontal resolution of a few hundred metres, resulting from the high sampling frequency of these instruments $(0.5-2 \mathrm{~Hz})$. Therefore, the aircraft observations are able to sample the small-scale variability of the tracers.

The SAGE III Ozone Loss and Validation Experiment (SOLVE) sought to establish a comprehensive data set of UTLS trace gases and meteorological data in the northern polar regions, including latitudinal gradients across the polar vortex. Measurements were made in the Arctic high-latitude region during winter 1999-2000 using the NASA DC-8 and ER-2 aircraft, as well as balloon platforms and ground-based instruments. $\mathrm{CO}_{2}, \mathrm{CH}_{4}$, and $\mathrm{N}_{2} \mathrm{O}$ were measured by several instruments and used to calculate a composite mean age (as in Andrews et al., 2001b, using earlier measurements).

In situ balloon-based $\mathrm{CO}_{2}$ profile measurements are also used as a basis for comparisons with the reconstructed $\mathrm{CO}_{2}$ from the Lagrangian transport model. The data sets used in this study are high-quality observations with sufficient altitude coverage. They are measurements of whole air samples collected cryogenically from balloons or in situ measurements on-board a balloon gondola (Engel et al., 2009; Ray et al., 2014). Four balloon flights were selected for which a full $\mathrm{CO}_{2}$ profile is available (1) at Fort Sumner, New Mexico, USA $\left(34.5^{\circ} \mathrm{N}\right)$, on 17 September 2004; (2) at Sanriku, Japan $\left(39.33^{\circ} \mathrm{N}\right)$, on 30 May 2001; (3 and 4) and at Aire-surl'Adour, France $\left(43.75^{\circ} \mathrm{N}\right)$, on 24 September 2002 and 9 October 2001, respectively. Note that most profile observations are from the May-October period, when stratospheric variability in the Northern Hemisphere is expected to be lower than during the winter period. The combined measurements of $\mathrm{CO}_{2}$ and $\mathrm{SF}_{6}$ were used by Engel et al. (2009) to derive the mean age of the air, but here we focus on $\mathrm{CO}_{2}$.

A further data set, based on the CONTRAIL experiment (Machida et al., 2008) was used in the validation process of the reconstructed $\mathrm{CO}_{2}$ in the whole troposphere $(6-13 \mathrm{~km})$ from $20^{\circ} \mathrm{S}$ to $60^{\circ} \mathrm{N}$ during November 2005-2009. $\mathrm{CO}_{2}$ mixing ratios were measured during regular flights by Japan Airlines from Japan to Australia, Europe, North America, and Asia with continuous measuring equipment (CME) for in situ $\mathrm{CO}_{2}$ observations, as well as improved automatic air sampling equipment (ASE) for flask sampling (for more details about the instrument see Machida et al. (2002)). This data set provides significant spatial coverage, particularly in the Northern Hemisphere (Sawa et al., 2008).

\section{Method of global $\mathrm{CO}_{2}$ reconstruction}

To calculate the global $\mathrm{CO}_{2}$ distribution, air parcels are distributed from the upper troposphere to the stratosphere and integrated backward in time.

\subsection{Global backward trajectory}

Backward deterministic trajectories were calculated using the Lagrangian transport model, TRACZILLA (Legras et al., 2005), which is a modified version of FLEXPART (Stohl et al., 2005). TRACZILLA uses analysed winds to move air parcels in the horizontal direction and performs direct interpolation from data on hybrid levels. In the vertical direction, we used potential temperature coordinates and total heating rates. We denote the trajectories as diabatic following a convention established by Eluszkiewicz et al. (2000). At each level in the vertical, trajectories are initially distributed over a longitude-latitude grid with $2^{\circ}$ resolution in latitude and an almost uniform spacing in longitude of $2^{\circ} / \cos (\phi)$, where $\phi$ is the latitude, generating 10255 air parcels on each level from pole to pole. For the sake of simplicity, the vertical levels of the initial grid are chosen to be the hybrid levels of the ECMWF model. In order to encompass the whole stratosphere at any latitude and longitude, 30 levels from about $400 \mathrm{hPa}$ (varying according to the surface pressure) to $2 \mathrm{hPa}$ were selected. Above $56 \mathrm{hPa}$, the hybrid levels are reduced to pure pressure levels. Trajectories ending below the tropospheric boundary condition at $500 \mathrm{hPa}$, at which we assign the free tropospheric $\mathrm{CO}_{2}$ to each trajectory, were discarded during the initialization. Trajectories ending above this boundary are integrated backward in time up to 10 years or until they cross the boundary condition. In practice, stratospheric trajectories reach this boundary shortly (less than 2 months) after crossing the tropopause. Ensembles of trajectories were launched at the end of every month over the period 2000-2010 (Diallo et al., 2012).

\subsection{Calculation of global $\mathrm{CO}_{2}$}

Once a parcel has reached the tropospheric boundary condition at $500 \mathrm{hPa}$ at a given time and a given location, its $\mathrm{CO}_{2}$ mixing ratio is assigned according to the mixing ratio at that time and that location calculated from CarbonTracker and WDCGG. CarbonTracker was chosen when a back trajectory reached the tropospheric boundary after 1 January 2000 and WDCGG was chosen when it was impacted before this date. Since WDCGG provides surface data only, it was assumed that the vertical transport was fast in the lower troposphere and induced only a negligible bias at $500 \mathrm{hPa}$ in the $\mathrm{CO}_{2}$ mixing ratio, which was well verified (not shown) in the inner tropical region where most parcels reach the boundary. The assigned value was then used to reconstruct the $\mathrm{CO}_{2}$ mixing ratio at the location and time of the trajectory initialization. 


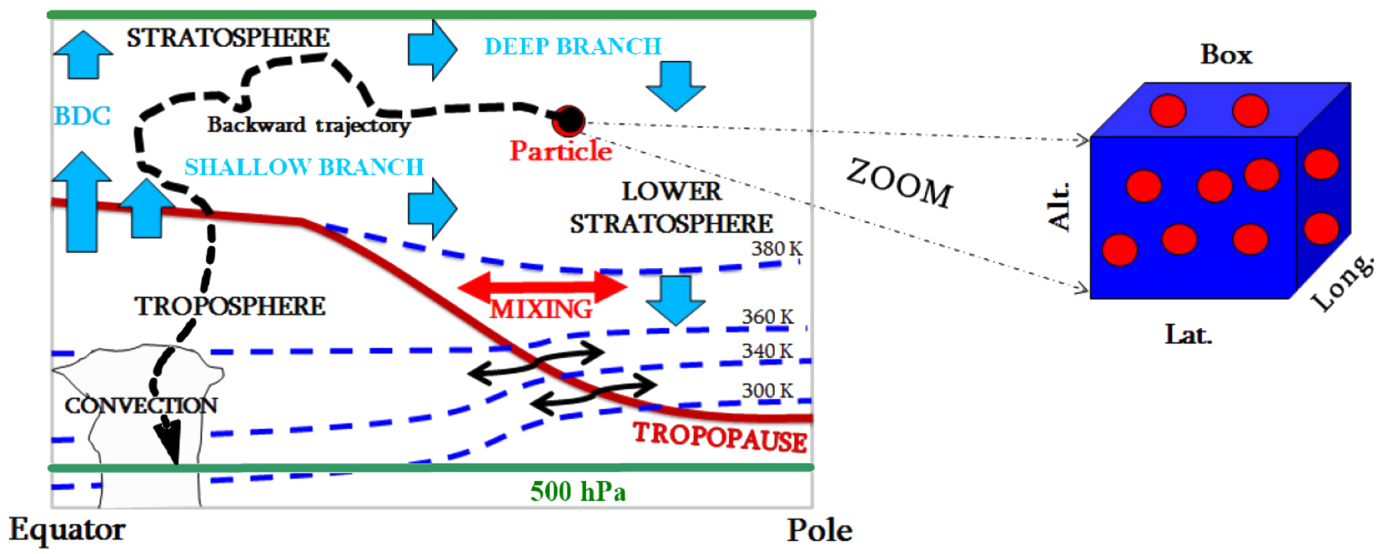

Figure 1. A schematic representation of the backward Lagrangian trajectories of air parcels starting in a (latitude $\times$ longitude $\times$ altitude) grid box. Here the longitudinal extend of the box should be seen as the whole latitudinal circle.

The monthly zonal mean $\mathrm{CO}_{2}$ for a given bin in latitude and altitude was calculated as the average over all longitudes of the trajectories initialized within this bin (Fig. 1). The latitudinal resolution of the bins is centred $2^{\circ}$ equatorward of $68^{\circ}$ and decreases near the poles $\left(69-73^{\circ}, 73-77^{\circ}, 77-81^{\circ}\right.$, $\left.81-90^{\circ}\right)$. For each date, the average is made over 180 air parcels at the equator and 67 air parcels at $68^{\circ} \mathrm{N}$ or S. Near the poles, towards which the number of trajectories launched per degree of latitude decreased to zero, larger intervals were chosen to maintain a sufficiently large number of trajectories in the bins. This calculation uses the same approach as Sect. 2.3 of Diallo et al. (2012). Further averaging over time is performed to improve statistics and to reduce noise. These averaging procedures are a simple way to account for mixing in the stratosphere and gather a distribution of air parcels with different histories within each bin.

As observed by Scheele et al. (2005), the number of backward trajectories launched on a given date and remaining within the stratosphere after some residence time, $\tau$, decreases exponentially with $\tau$. Diallo et al. (2012) showed that this relationship held for $\tau>3$ year with an exponential decay parameter $(b)$ equal to $0.2038 \mathrm{yr}^{-1}$ using ERAInterim winds and heating rates. The standard deviation of the mean (where each month was considered separately) decayed at the same rate. After 10 years, $88 \%$ of the particles initialized in the stratosphere reached the troposphere. We followed Scheele et al. (2005) in using this property to correct the estimated $\mathrm{CO}_{2}$ for the truncation of trajectory lengths at 10 years. If we define $G(J \mid t, \tau)$ as the probability density of the residence time $\tau$ at time $t$ for parcels launched in the bin $J$, the monthly mean stratospheric $\mathrm{CO}_{2}$ mixing ratio is

$\overline{\mathrm{CO}_{2}(J, t)}=\int_{0}^{\infty} \mathrm{CO}_{2}{ }^{T}(t-\tau) G(J \mid t, \tau) d \tau$,

where $\mathrm{CO}_{2}{ }^{T}$ is the tropospheric mixing ratio of $\mathrm{CO}_{2}$, which is assumed here to be uniform for simplicity. The truncated version of this integral, up to $t_{f}=10 \mathrm{yr}$, can be calculated explicitly from the backward trajectories as a mean for all parcels from bin $J$, which hit the $500 \mathrm{hPa}$ surface weighted by their proportion among all launched parcels in bin $J$. Assuming that $G(J \mid t, \tau)=G\left(J \mid t, t_{f}\right) \exp \left(-b\left(\tau-t_{f}\right)\right)$ for $t>$ $t_{f}$, with $\mathrm{CO}_{2}{ }^{T}$ governed by an annual modulation added to a linear growth, $\mathrm{CO}_{2}{ }^{T}(\tau)=p_{0}+p_{1} \times \tau+a_{0} \times \cos (2 \pi(\tau-\varphi))$, the monthly mean $\mathrm{CO}_{2}$ mixing ratio can be estimated as

$$
\begin{aligned}
\overline{\mathrm{CO}_{2}}(J, t)= & \int_{0}^{t_{f}} \mathrm{CO}_{2}{ }^{T}(t-\tau) G(J \mid t, \tau) d \tau+\frac{G\left(J \mid t, t_{f}\right)}{b} \\
& \left\{\left(p_{0}+p_{1}\left(t-t_{f}-\frac{1}{b}\right)\right)+\right. \\
& \frac{b a_{0}}{b^{2}+4 \pi^{2}}\left[b \cos \left(2 \pi\left(t-t_{f}-\varphi\right)\right)+2 \pi\right. \\
& \left.\left.\sin \left(2 \pi\left(t-t_{f}-\varphi\right)\right)\right]\right\}
\end{aligned}
$$

where all times are in years. The contribution of the remaining air parcels after 10 years of backward motion was thus accounted for by the integrated term in Eq. (2), where $G\left(J \mid t, t_{f}\right) / b$ is the proportion of parcels in the bin that have not hit the $500 \mathrm{hPa}$ surface at time $t_{f}$. The coefficients $p 0, p 1, a_{0}$, and $\varphi$ are estimated by fitting the Mauna Loa $\mathrm{CO}_{2}$ data. The correction can also be applied below the tropopause since the only tropospheric parcels that live for $10 \mathrm{yr}$ without hitting the $500 \mathrm{hPa}$ surface are among those that have been entrained in the stratosphere.

\subsection{Validations of the global reconstruction method}

The reconstruction during SOLVE and in situ balloon campaigns are used to validate the global reconstruction of $\mathrm{CO}_{2}$ and the ability of TRACZILLA to reproduce the small-scale $\mathrm{CO}_{2}$ variations along the flight tracks. 


\subsubsection{Reconstruction of $\mathrm{CO}_{2}$ along aircraft flight track and balloon profiles}

The procedure used here differs from that of the global reconstruction described above in three main respects. First, the parcels were initialized at locations distributed along the flight track or the balloon profile. In the case of the ER-2 flights, parcels were released with the frequency of the measurement, at $0.25 \mathrm{~Hz}$ (Daube et al., 2002), amounting to 900 locations per flight hour. In the case of the balloon flight (Engel et al., 2009), the air parcels were distributed along the balloon profile with a frequency higher than the tracer measurements. Namely, they were released at 200 locations in the vertical, regularly distributed in log pressure between 500 and $1 \mathrm{hPa}$ at the same latitude-longitude position as the balloon.

Second, we take into account that a single sample can be understood as a mixture of sub-parcels arising from a large number of origins. The simplest representation of this mixing is by a constant diffusion, which mainly acts in the vertical direction, and it is well known that such a process can be represented by a Wiener process. Therefore, following Legras et al. (2005), we released a large number of air parcels (200 for the ER-2 flights, 5000 for the balloon profiles) from each measurement location. The Lagrangian advection was modified such that on a time step $\delta t$ the motion of a given parcel located in $X$ is

$\delta X=u(X, t) \delta t+\delta \eta \boldsymbol{k}$,

where $u$ is the wind fields, $\boldsymbol{k}$ is the vertical unit vector, and $\delta \eta \equiv w(t) \delta t$ is the product of the time step $\delta t$ and a Wiener process $w$ approximated by 50 iterations of the white noise during a time step. In the small $\delta t$ limit, this is equivalent to a diffusion $D=\frac{1}{2}<w^{2}>\delta t$. The well-posedness in the backward time direction arises from the adjoint equation of the Green function of advection-diffusion (for more details see Legras et al., 2005). The value $D$ in the lower stratosphere was estimated (Legras et al., 2005; Pisso and Legras, 2008) by comparing the observed small-scale tracer fluctuations and their reconstructions. The resulting value is $D \approx 0.1 \mathrm{~m}^{2} \mathrm{~s}^{-1}$, which is applied to the whole atmosphere in the present study. Physically, this turbulent diffusion, which is about 4 orders of magnitude larger than the molecular diffusion of $\mathrm{CO}_{2}$ in the air $\left(1.610^{-5} \mathrm{~m}^{2} \mathrm{~s}^{-1}\right.$ Haynes and Lide, 2012), accounts for the small-scale motion missing in the ERA-Interim reanalysis winds. It is noticeable that the diffusion is effective at dispersing the clouds of parcels emitted from a single location only for a few days, after which dispersion by the resolved wind strain dominates.

Third, the trajectories were integrated backward for 6 months, after which the $\mathrm{CO}_{2}$ mixing ratio was assigned according to the zonal mean $\mathrm{CO}_{2}$ value calculated from the global reconstruction at that time and at the locations of the parcels. The mean value and confidence interval were calculated over all the initialized particles. The air parcels that reached the $500 \mathrm{hPa}$ level were assigned the $\mathrm{CO}_{2}$ mixing ratio on that surface.

\section{Comparison of observations and model reconstructions}

In this section, we test the realism of $\mathrm{CO}_{2}$ reconstructions against several observation data sets that span a large range of scales, geographical locations, and altitudes.

\subsection{SOLVE campaign}

Figure 2 shows observed and reconstructed $\mathrm{CO}_{2}$ mixing ratio time series from 16 flights during the SOLVE campaign. Figure 3 compares the observed versus reconstructed $\mathrm{CO}_{2}$ mixing ratios for each flight along with correlation coefficients and mean distances ( $\Delta$ in ppmv), defined as the sum of the absolute difference between the observed and the reconstructed values divided by the number of recorded values. The flight patterns include test flights at subtropical (11 and 16 December 1999, 6 January 2000) and mid-latitudes (11 January 2000), transit flights between mid- and high latitudes (14 January, 16 March 2000), and flights inside the polar vortex or across its edge (all other dates). In nearly all of the flights, the observed $\mathrm{CO}_{2}$ falls within the $95 \%$ confidence interval of the reconstruction. It can be seen from Fig. 3 that the correlation is not a good indicator of the similarity between the observed and the reconstructed curves because it can be high due to trends, even for cases that exhibit large differences, such as 3 February 2000 . The $\Delta$ value is a much better metric of the agreement between the observed and reconstructed $\mathrm{CO}_{2}$. In 6 cases out of 16 the agreement is excellent, with $\Delta \leq 0.36 \mathrm{ppmv}$, and the two curves agree fairly well even for the magnitude of small-scale fluctuations. In four other cases with $0.49 \leq \Delta \leq 0.61 \mathrm{ppmv}$, the two curves stay very close, with only a few features missed by the reconstruction. In two other cases with $0.66 \leq \Delta \leq 0.67 \mathrm{ppmv}$, the reconstruction shows some larger deviations from the observations. On 11 December 1999, the reconstruction missed the decrease in $\mathrm{CO}_{2}$ as the plane ascended at the beginning of the flight and then stayed slightly too high for the subsequent horizontal lag. The 27 January 2000 case is a flight from the inside of the polar vortex to the outside, which was poorly reconstructed for the outside part between 10:30 UTC and 13:00 UTC. Using similar methods, Legras et al. (2005) showed that the stratospheric tracers $\mathrm{O}_{3}$ and $\mathrm{N}_{2} \mathrm{O}$ could be reconstructed for this flight, but they also found a large standard deviation for the outside section where filaments of polar and extratropical air were interleaved. The flights with the largest discrepancies $(\Delta>0.74$ ppmv $)$ on 14 January, 3 February, and 7 and 16 March 2000 can be explained by flight tracks that followed the edge of the polar vortex. In these flights, the reconstruction is very sensitive to any misplacement of the vortex edge in the reanalysis and thus not 

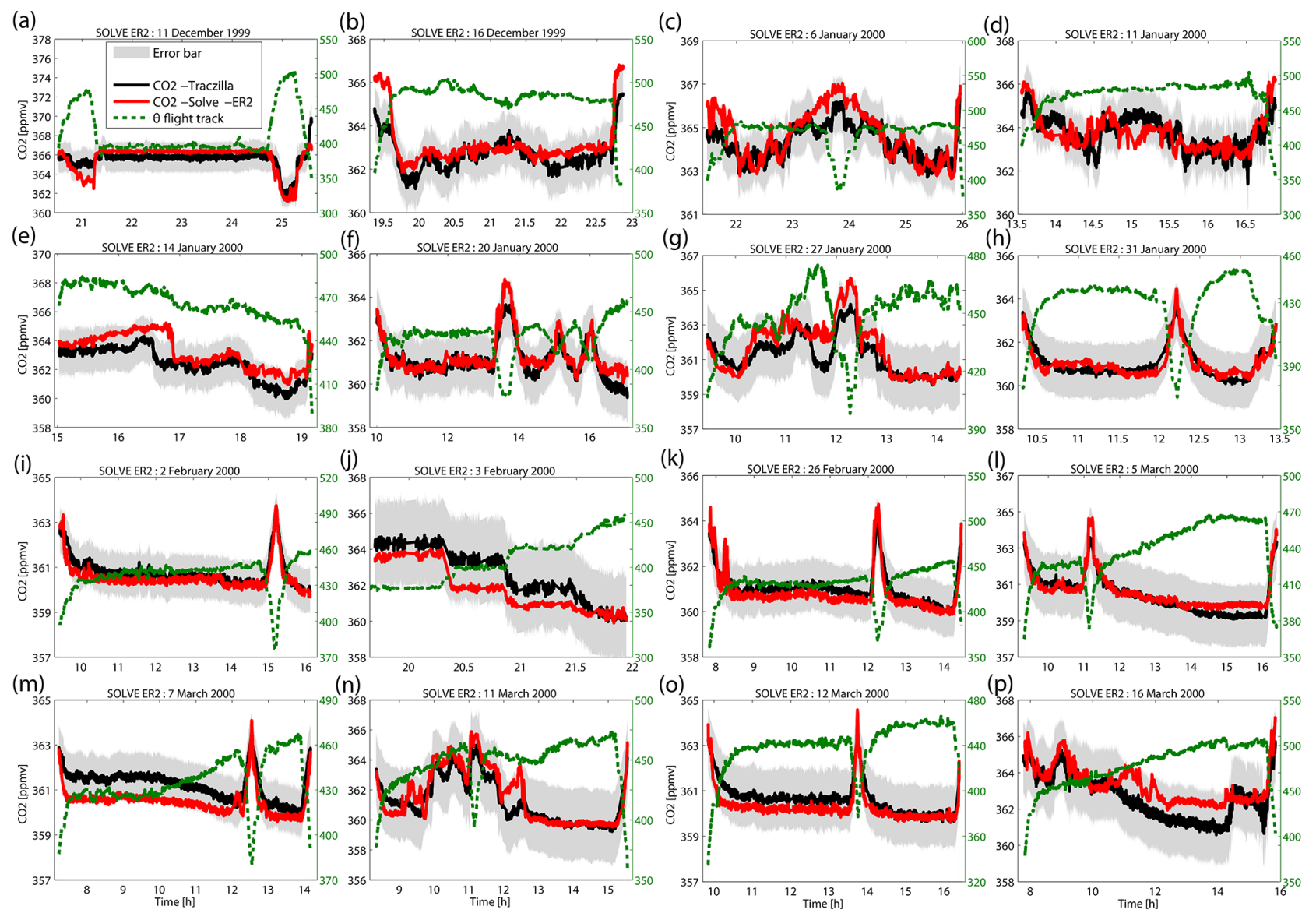

Figure 2. Comparison of the reconstructed monthly mean $\mathrm{CO}_{2}$ from backward trajectories with aircraft measurements from the SOLVE campaign (Daube et al., 2002). Black shows reconstructed mean $\mathrm{CO}_{2}$ along the ER-2 flight track using the TRACZILLA Lagrangian transport model. Red shows observed mean $\mathrm{CO}_{2}$. Green shows potential temperature of the ER-2 flight track. The grey shaded area indicates the $95 \%$ confidence interval calculated from the reconstruction.

useful as an evaluation of the reconstructed $\mathrm{CO}_{2}$. In addition, it is important to emphasize that the value of the applied diffusion $\left(D \approx 0.1 \mathrm{~m}^{2} \mathrm{~s}^{-1}\right)$ allows the reconstruction to fit the observed small-scale variability $(\sim 1 \mathrm{~km})$. See Legras et al. (2005) for a complete discussion on this matter.

\subsection{Balloon vertical profiles}

In order to test the reconstruction over a larger vertical range of altitude, Fig. 4 shows a comparison of the vertical profiles of the reconstructed mean $\mathrm{CO}_{2}$ by TRACZILLA with the observations of four mid-latitude stratospheric balloon flights (Engel et al., 2009; Ray et al., 2014). For three of the cases, most of the measurements fall within the $95 \%$ confidence interval of the reconstructed profiles and the local maxima at 23 and $18 \mathrm{~km}$ in Fig. 4c, d, respectively, are well reproduced. These three profiles have relatively large $\mathrm{CO}_{2}$ mixing ratios in the troposphere in common, which decrease with altitude. However, the reconstructed profile in Fig. $4 \mathrm{~b}$ is 1 ppmv smaller on average than the observed pro- file and misses the large fluctuations above $20 \mathrm{~km}$. This flight was performed from Aire-sur-l'Adour (France) when a cold front crossed the region, with strong local tracer gradients in the lower stratosphere, as seen in the potential vorticity map shown in the panel. In order to test the spread induced by this meteorological structure, we have reconstructed eight vertical profiles at $1^{\circ}$ distance around the initial profile. However, the observed spread among this ensemble of profiles is too small to explain the discrepancy in Fig. 4b. Notice that $\mathrm{SF}_{6}$-derived mean ages are in good agreement with the reconstructed mean age of Diallo et al. (2012). Therefore, we are left without any satisfactory explanation for this case but to assume some undocumented instrument malfunction.

\subsection{Temporal series}

To obtain additional details about the upward propagation of the tropospheric $\mathrm{CO}_{2}$ seasonal cycle into the LMS and to evaluate the model near the lower boundary condition and the tropical tropopause, we compare the time series of the 


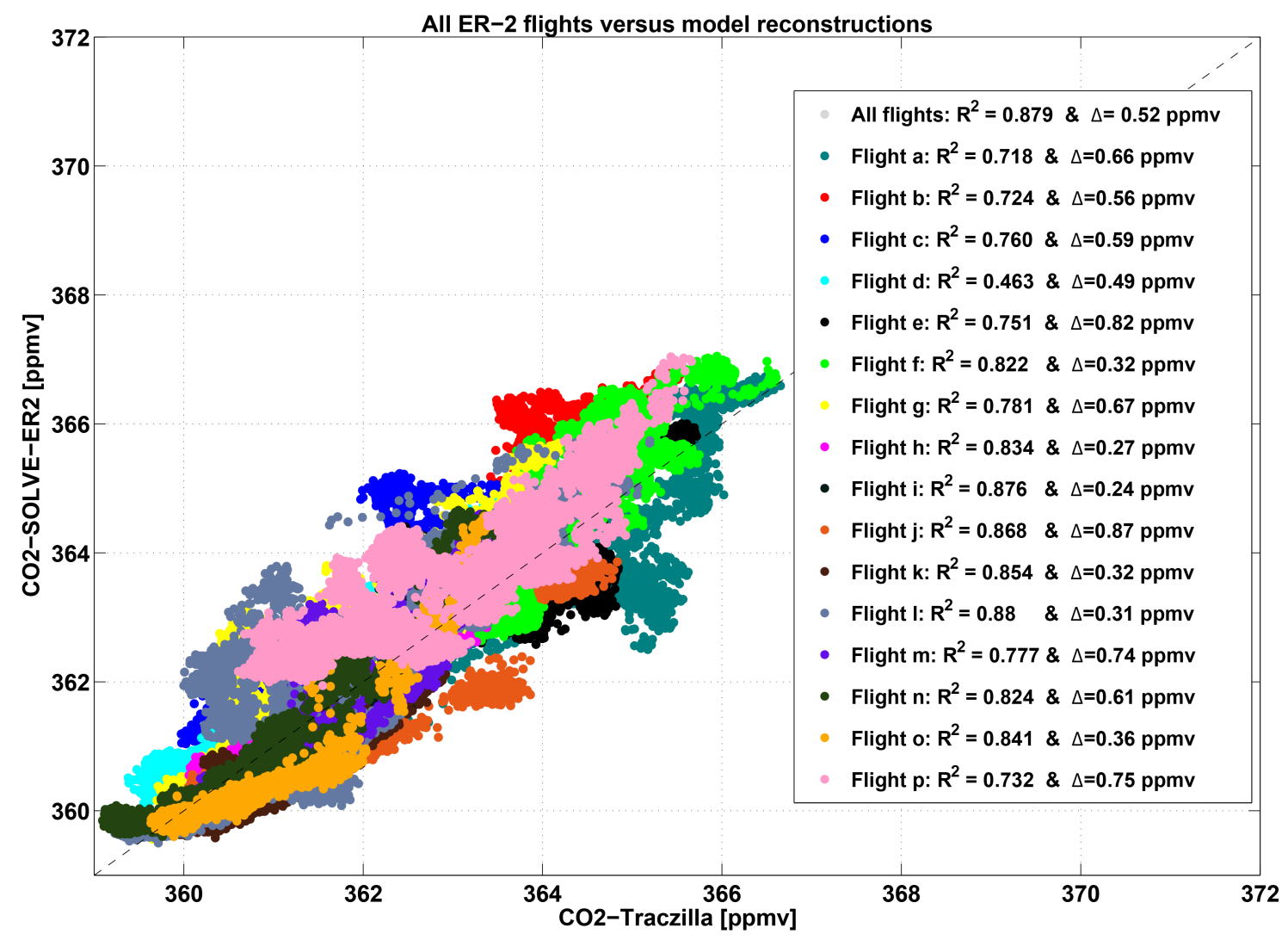

Figure 3. Comparison of the reconstructed monthly mean $\mathrm{CO}_{2}$ from the backward trajectories with aircraft measurements from the SOLVE campaign (Daube et al., 2002). Colours indicate different flights in Fig. 2. R-squared and the $\Delta$ (in ppmv), defined as the mean of the absolute value of model-observation differences, are shown in the legend. The dashed line is the $1: 1$.

reconstructed monthly mean $\mathrm{CO}_{2}$ (Sect. 3.2) with the observations.

Figure 5a compares the time series of modelled monthly mean $\mathrm{CO}_{2}$ with the measurements from CONTRAIL (Sawa et al., 2008, 2012) in the tropical region $10^{\circ} \mathrm{S}-20^{\circ} \mathrm{N}$ and in the vertical range 7-9 km between November 2006 and January 2010. The comparison shows the ability of the model to capture the tropospheric $\mathrm{CO}_{2}$ seasonal variation and validates the tropospheric boundary condition.

Figure $5 \mathrm{~b}$ compares the modelled monthly mean $\mathrm{CO}_{2}$ time series in the altitude bin $16-17 \mathrm{~km}$ and between $10^{\circ} \mathrm{S}$ and $20^{\circ} \mathrm{N}$ just below the tropical tropopause, where the tropospheric air enters the stratosphere, with the average of ground-based $\mathrm{CO}_{2}$ data from Mauna Loa $\left(19^{\circ} \mathrm{N}\right)$ and American Samoa $\left(14^{\circ} \mathrm{S}\right)$ delayed by 15 days. We find, consistent with Boering et al. (1996) and Andrews et al. (1999, $2001 \mathrm{a}, \mathrm{b}$ ), that the amplitude of the two signals is the same, and we diagnose a delay of 2 months at a higher altitude in the layer 18-19 km (not shown) in agreement with Boering et al. (1996). The shorter timescale below the tropopause is in agreement with other studies (Bergman et al., 2012; Tissier and Legras, 2016).
Figure $5 \mathrm{c}$ shows the modelled monthly mean $\mathrm{CO}_{2}$ in the latitude bin $50-60^{\circ} \mathrm{N}$ at different altitudes in the range 7$13 \mathrm{~km}$ between November 2005 and January 2010. These curves are compared with CONTRAIL measurements in the same latitude band (Sawa et al., 2008). The modelled and measured $\mathrm{CO}_{2}$ differ by less than 1 ppmv, except for a few isolated months such as March 2006 and March 2009 and outliers such as April at $12-13 \mathrm{~km}$. There is a shift on the order of 4-6 months in the mean $\mathrm{CO}_{2}$ seasonal cycle above $11-12 \mathrm{~km}$, in the lowermost extratropical stratosphere, with respect to the tropospheric signal. This is due to the delay induced by the shallow branch of the BDC also found by Bönisch et al. (2009) and Sawa et al. (2008). The discrepancies are concentrated during the spring season, during which large gradients of $\mathrm{CO}_{2}$ span the region, as discussed in Sect. 5.

\section{Global distribution of zonal mean $\mathrm{CO}_{2}$}

The zonal mean distribution of $\mathrm{CO}_{2}$ illustrates the main features of the BDC, such as mixing and transport variabilities through temporal and spatial evolution. Figure 6 illustrates the typical seasonal variation of the monthly mean $\mathrm{CO}_{2}$ de- 

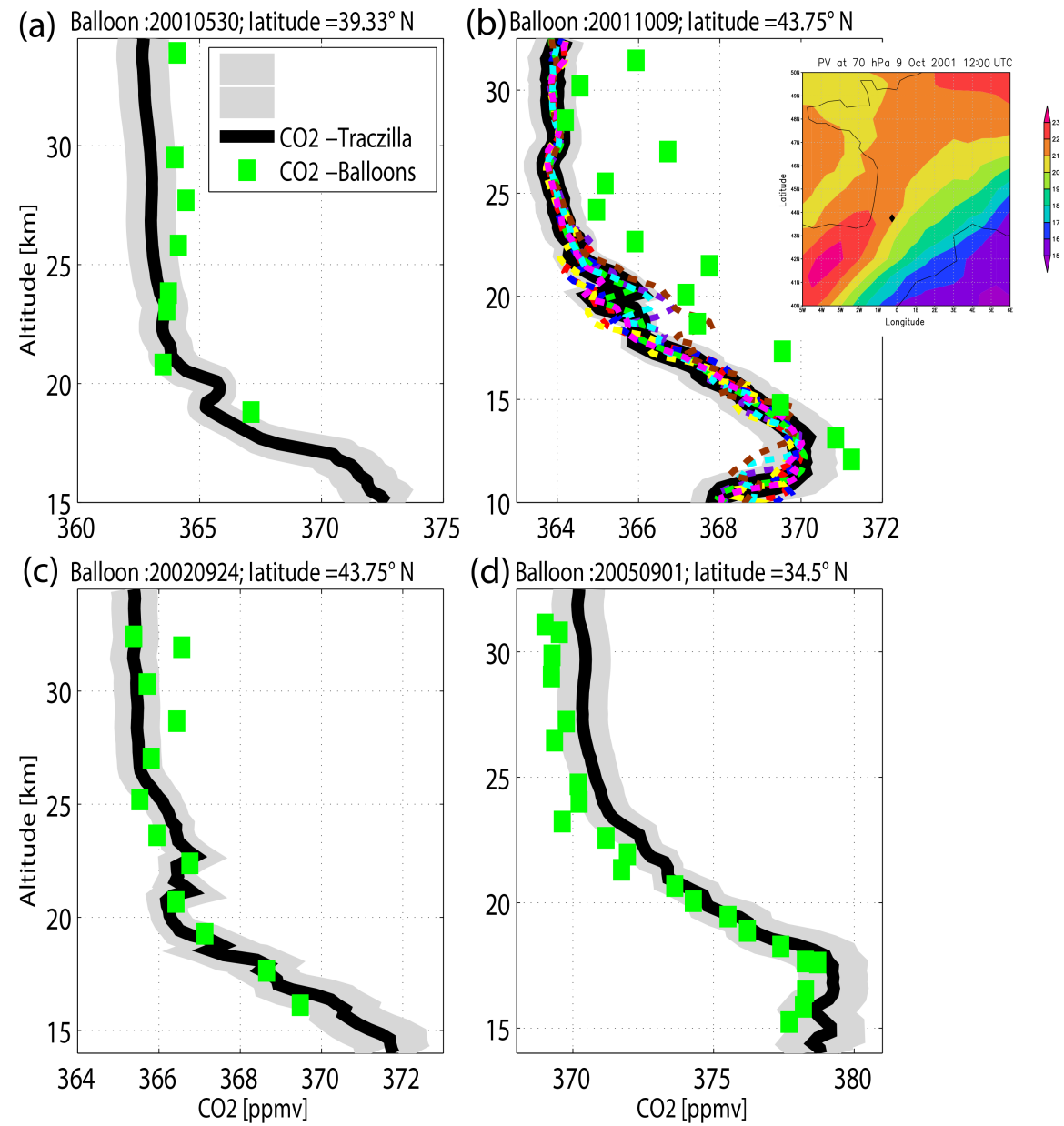

Figure 4. Reconstructed vertical profiles of the monthly mean $\mathrm{CO}_{2}$ compared with each in situ stratospheric balloon observation of $\mathrm{CO}_{2}$ (Engel et al., 2009). Black curves show reconstructed vertical profiles of mean $\mathrm{CO}_{2}$. Green squares show in situ balloon measurements of mean $\mathrm{CO}_{2}$. Grey shading shows the $95 \%$ confidence interval from the reconstruction. The measurements were taken from Sanriku, Japan $\left(39.33^{\circ} \mathrm{N}\right)$, on 30 May 2001 (a); Aire sur l'Adour, France $\left(43.75^{\circ} \mathrm{N}\right)$, on 9 October 2001 (b) and on 24 September 2002 (c); and Fort Sumner, New Mexico, USA $\left(34.5^{\circ} \mathrm{N}\right)$, on 1 September 2005 (d), respectively. The different dashed lines show the other eight reconstructed profiles surrounding the measurement on 9 October 2001. The insert on the upper right panel shows the potential vorticity (in PVU) on the $70 \mathrm{hPa}$ surface for 9 October 2001 at 12:00 UTC over France from ERA-Interim. The location of Aire sur l'Adour is indicated by a diamond.

rived from the Lagrangian reconstruction for 2010 as an example among the 11 years.

\subsection{Upper troposphere and lowermost stratosphere}

The zonal mean distribution of $\mathrm{CO}_{2}$ in the free atmosphere, especially above $5 \mathrm{~km}$, is driven by the large-scale transport processes. Fast quasi-isentropic mixing is combined with upwelling in the tropics and downwelling in the extratropical lowermost stratosphere. Figure 6a shows the meridional and vertical $\mathrm{CO}_{2}$ distribution during 6 different months in 2010 . In the Northern Hemisphere, the tropospheric monthly mean $\mathrm{CO}_{2}$ is dominated by a strong seasonal cycle, reflecting the biospheric activity. The terrestrial vegetation removes $\mathrm{CO}_{2}$ by photosynthesis during its growth phase and returns $\mathrm{CO}_{2}$ to the atmosphere when it dies and decomposes. $\mathrm{CO}_{2}$ concen- tration increases during autumn and winter to reach a maximum in April-May, followed by a rapid decay due to the spring biospheric bloom, and reaches a minimum in JulyAugust. The cycle is much weaker in the Southern Hemisphere and is influenced by transport from the Northern Hemisphere. The combined effect of fast isentropic mixing (Haynes and Shuckburgh, 2000a, b) and convection (Sawa et al., 2008) propagates the cycle towards the tropics, creating both a horizontal and vertical gradient (Nakamura et al., 1991; Bönisch et al., 2009; Sawa et al., 2012). From Fig. 6a, it is clear that during the Northern Hemisphere winter, the concentration tends to follow the isentropes in the extratropics for potential temperatures up to about $330 \mathrm{~K}$. The barrier effect of the subtropical jet (Miyazaki et al., 2009) generates a strong meridional gradient near $30^{\circ} \mathrm{N}$, which reaches 
(a)

CO2 near tropical tropospheric boundary condition $\left(10^{\circ} \mathrm{S}-20^{\circ} \mathrm{N}\right)$

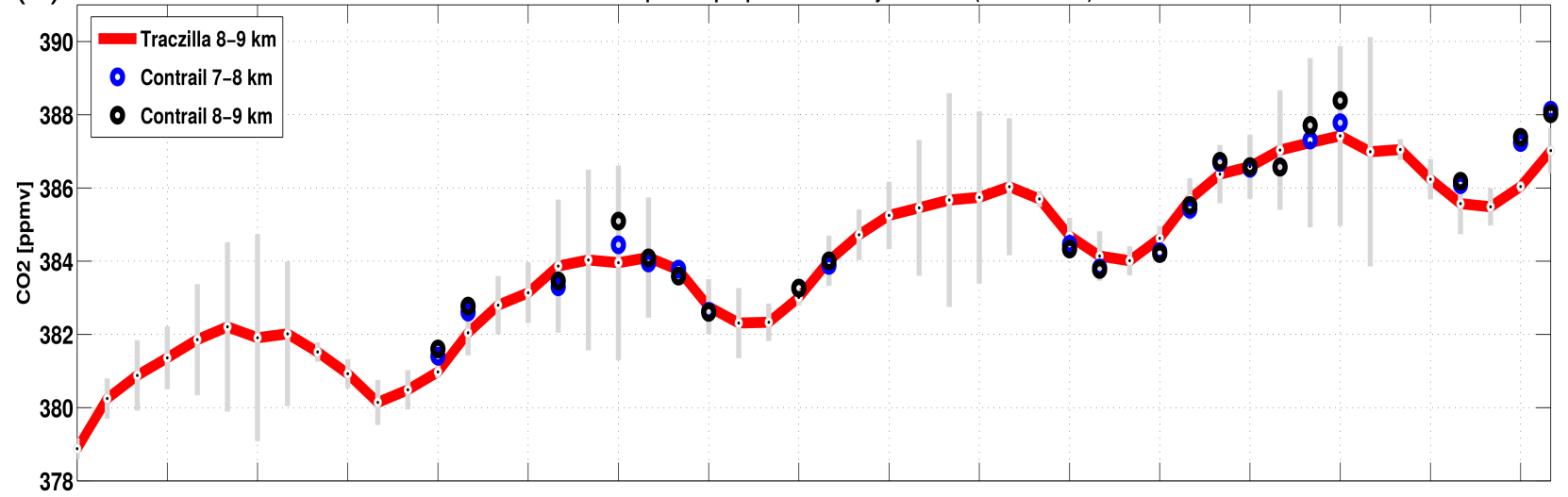

(b)
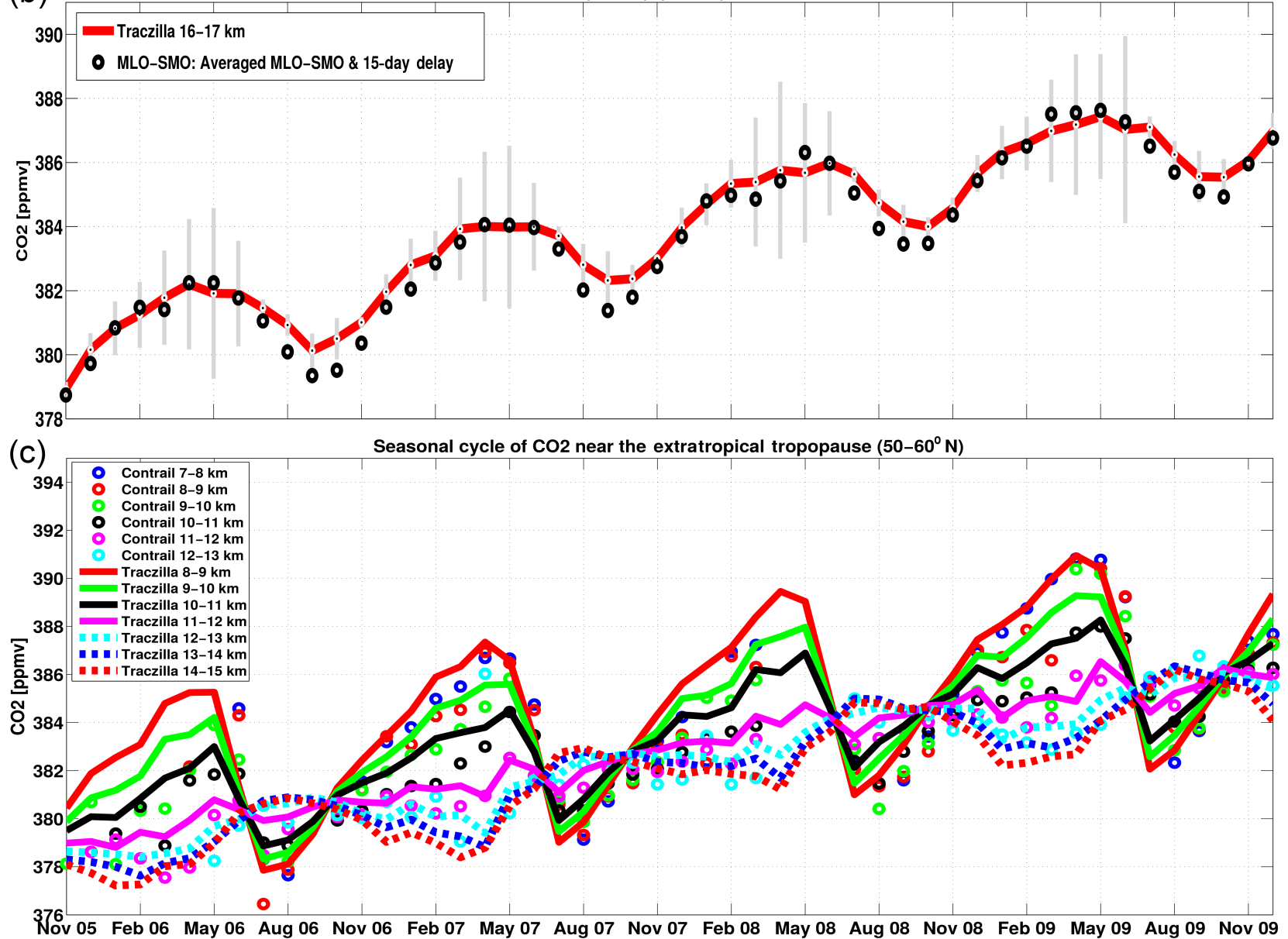

Figure 5. Temporal evolution of the monthly mean $\mathrm{CO}_{2}$ seasonal cycle from TRACZILLA calculations (line) compared with CONTRAIL and ground measurements (circle). (a) Comparison model with CONTRAIL in the tropospheric region above the tropospheric boundary in the latitude range $10^{\circ} \mathrm{S}-20^{\circ} \mathrm{N}$. (b) In the upper tropospheric region close to the tropical tropopause and the latitude range $10^{\circ} \mathrm{S}-20^{\circ} \mathrm{N}$, comparison with the average of surface station data at Mauna Loa, Hawaii $\left(19^{\circ} \mathrm{N}\right)$, and American Samoa $\left(14^{\circ} \mathrm{S}\right)$ delayed by 15 days. (c) Comparison model with CONTRAIL in the upper troposphere near the extratropical tropopause at $50-60^{\circ} \mathrm{N}$ and at several heights from 7 to $15 \mathrm{~km}$. The error estimated from the reconstruction is indicated as vertical grey bars.

a maximum near $350 \mathrm{~K}$. Once it has reached the tropics, $\mathrm{CO}_{2}$ is then transported upward by tropical convection and prop- agates into the stratosphere through the BDC. Throughout the summer (June, July, and August), while the tropospheric 
(a)
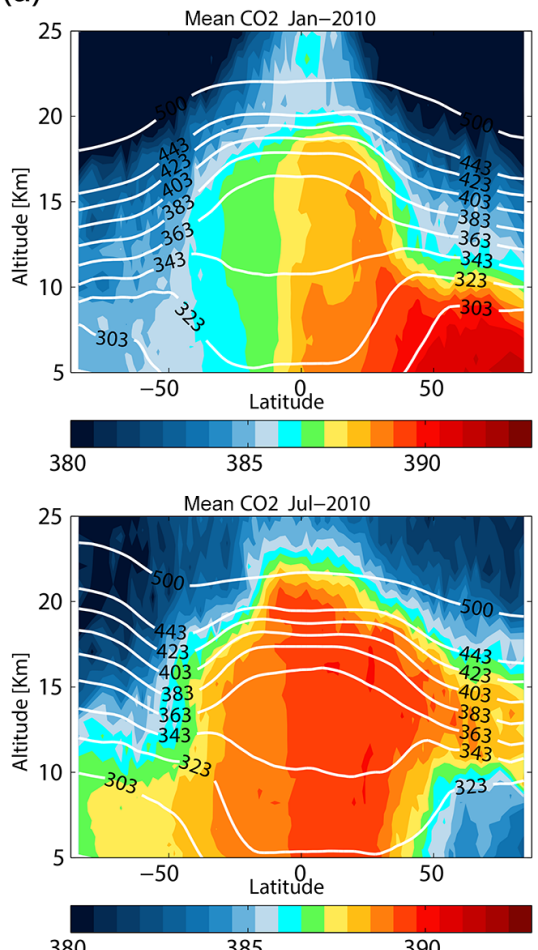

(b)
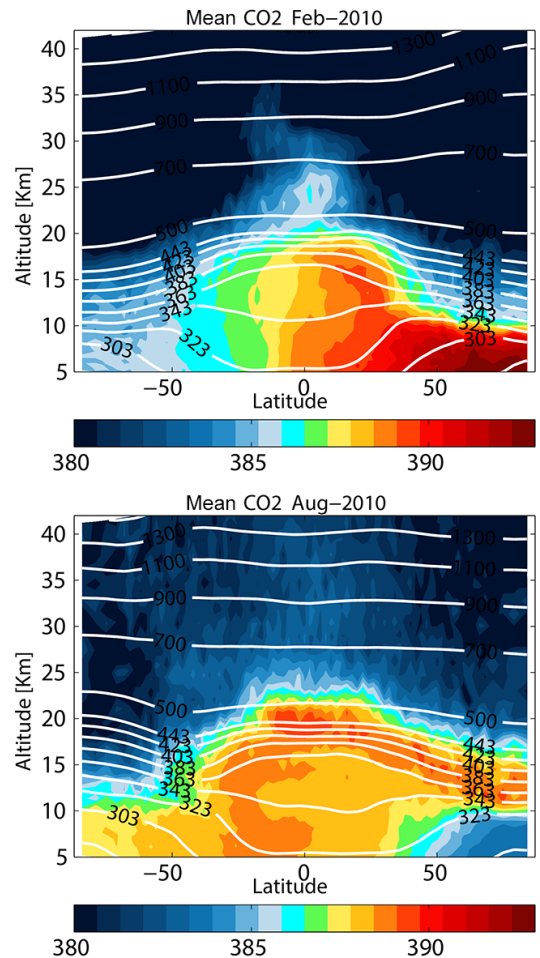
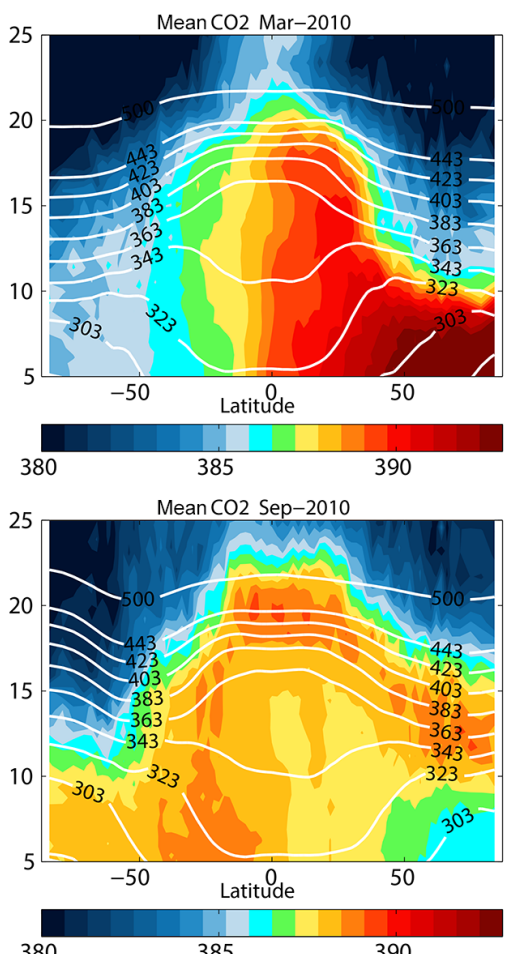

380

390
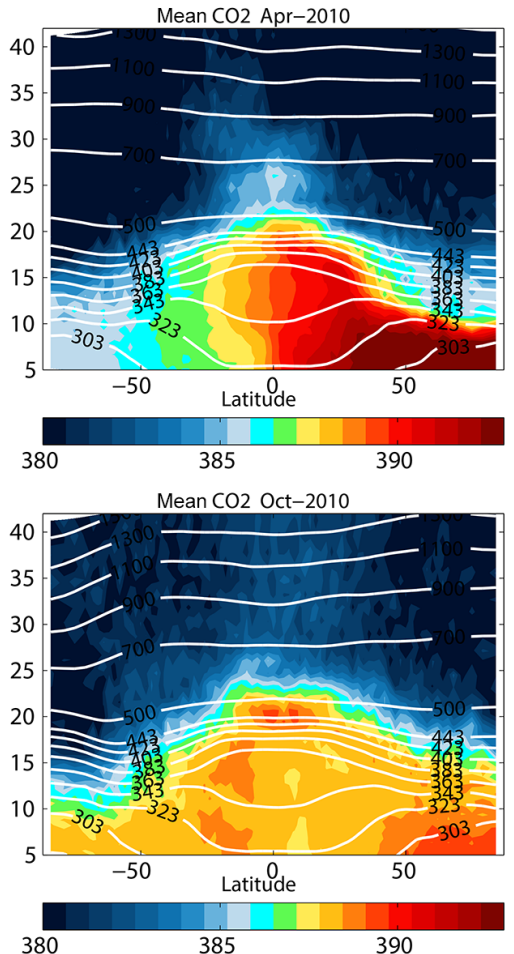
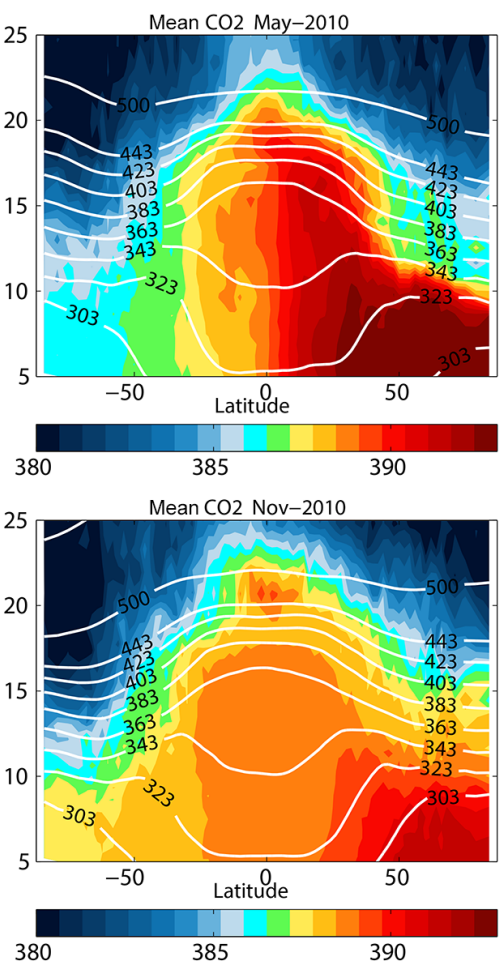

380

390

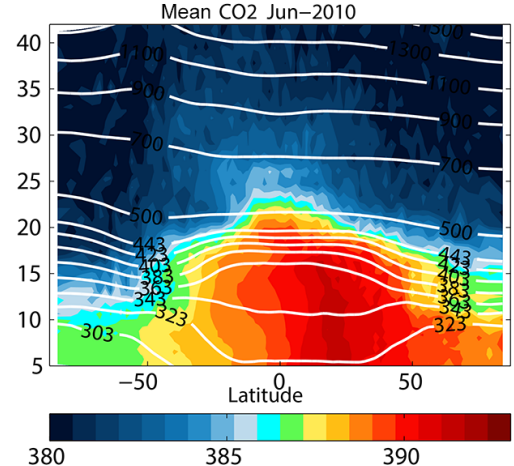

380

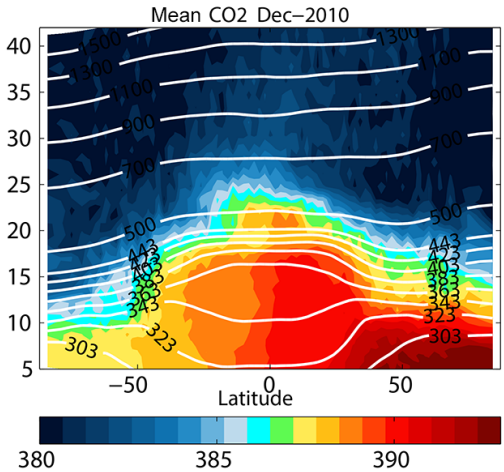

Figure 6. 

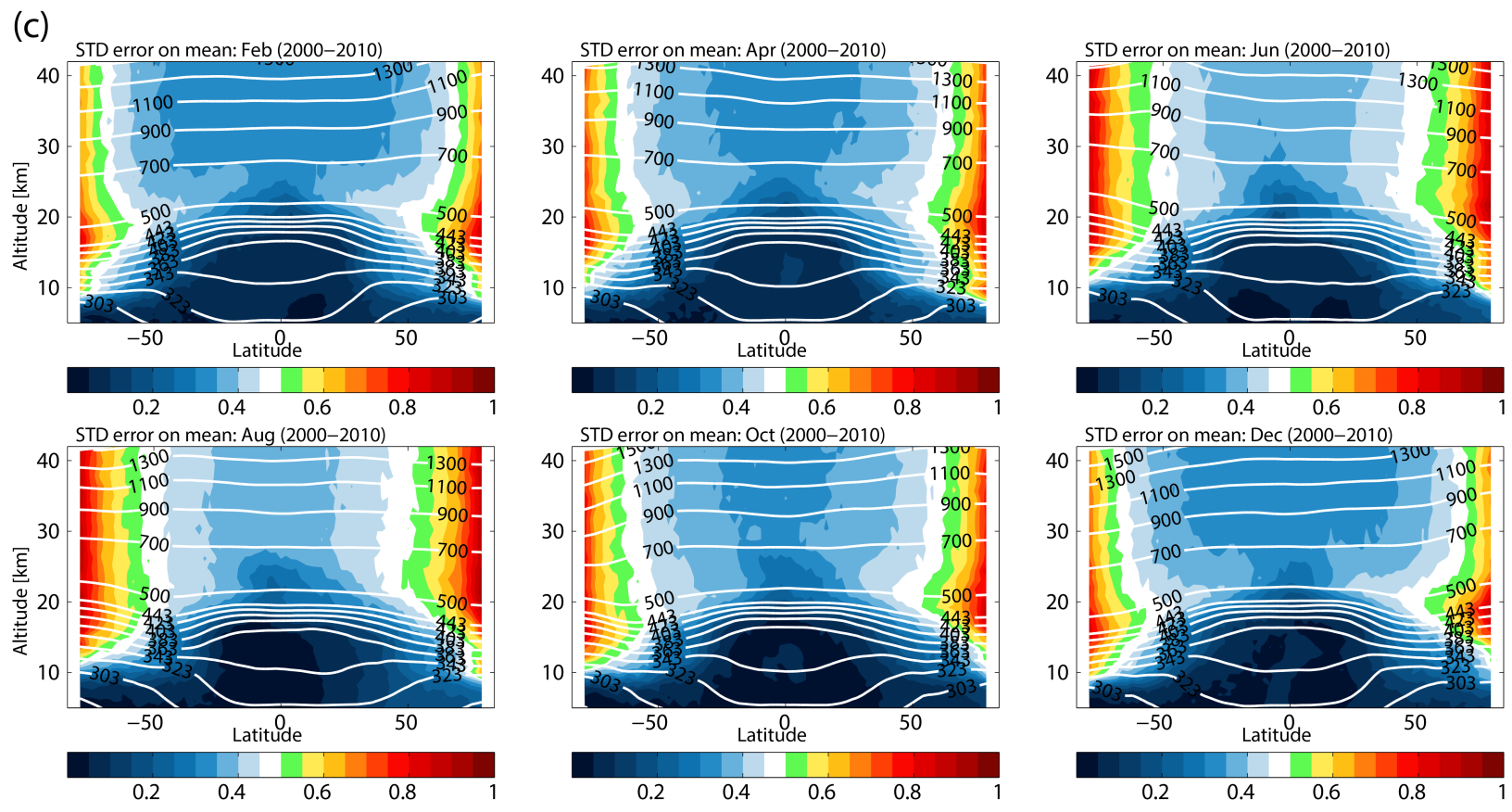

Figure 6. (a) Global distribution of the seasonal cycle of the reconstructed monthly mean $\mathrm{CO}_{2}$ (in ppmv) in the upper troposphere and the lower stratosphere from 5 to $25 \mathrm{~km}$ for the odd months of 2010. (b) Same as (a) but for the even months of 2010 and the altitude range from 5 to $45 \mathrm{~km} . \mathrm{CO}_{2}$ calculated on model levels is first interpolated to altitude levels using the latitude dependency of the zonally and monthly averaged geopotential. (c) The standard error of the mean $\mathrm{CO}_{2}$ over the 2000-2010 period. The white contours show the isentropic surfaces.

$\mathrm{CO}_{2}$ is removed from the atmosphere due to the biosphere activity, a layer of high $\mathrm{CO}_{2}$ extends from the tropics to the northern mid-latitudes into the lower stratosphere driven by the lower branch of the BDC (Bönisch et al., 2008). This transport is promoted by the Asian monsoon anticyclone, which traps young continental air lifted from the surface and induces a flux to the extratropical stratosphere on its west side as it is eroded across the jet (Dethof et al., 2000; Bannister et al., 2004; Park et al., 2007b, 2008, 2009, 2010; Randel et al., 2010; Pan et al., 2016). Due to the turnover time of this transport, the maximum concentration of $\mathrm{CO}_{2}$ in the northern lower stratosphere lags behind that at the surface by 4 to 6 months, and this concentration is essentially reached when the surface concentration is at its minimum. The result is an inverted vertical profile, which is at its maximum in July and persists over the summer. A qualitative comparison between the reconstructed $\mathrm{CO}_{2}$ in Fig. 6a and observations from Sawa et al. (2008) (see their Fig. 7) exhibits good agreement in the cycle of the tropospheric and lower stratospheric $\mathrm{CO}_{2}$, and in particular in the cycle of the inversion. There are, however, differences in the location and intensity of the meridional gradient, which might be due to the specific sampling by Sawa et al. (2008), and which gives a strong weight to the most intense region of the Pacific jet stream.

\subsection{Middle and upper stratosphere}

Figure $6 \mathrm{~b}$ shows the $\mathrm{CO}_{2}$ global distribution in the middle and upper stratosphere up to $42 \mathrm{~km}$ for even months in 2010 . As the tropospheric seasonal cycle is transported into the middle and upper stratosphere through the tropical pipe, its amplitude decreases upward because of the combined effect of the upwelling branch of the BDC and mixing processes. The deep branch of the BDC is much slower than the shallow branch and old air with low $\mathrm{CO}_{2}$ concentrations in the middle and upper stratosphere. Younger air with high $\mathrm{CO}_{2}$ is isolated in the tropical area, an effect that is at a maximum during northern hemispheric winter, in agreement with the age of the air calculations ( $\mathrm{Li}$ et al., 2012; Diallo et al., 2012). The horizontal mixing homogenizes $\mathrm{CO}_{2}$ in the midand high latitudes during summer. Because of this prior mixing, the winter containment within the polar vortex generates only a weak polar minimum (and no localized horizontal gradient averaged over the latitude circle and it does not follow the $\mathrm{CO}_{2}$ or potential vorticity contours).

\subsection{Uncertainty about $\mathrm{CO}_{2}$ global distribution}

Figure $6 \mathrm{c}$ shows the monthly averaged uncertainties about the reconstructed monthly zonal mean $\mathrm{CO}_{2}$ over the 2000 2010 period calculated from the trajectories. The uncertainty is estimated as the standard error of the mean by assum- 

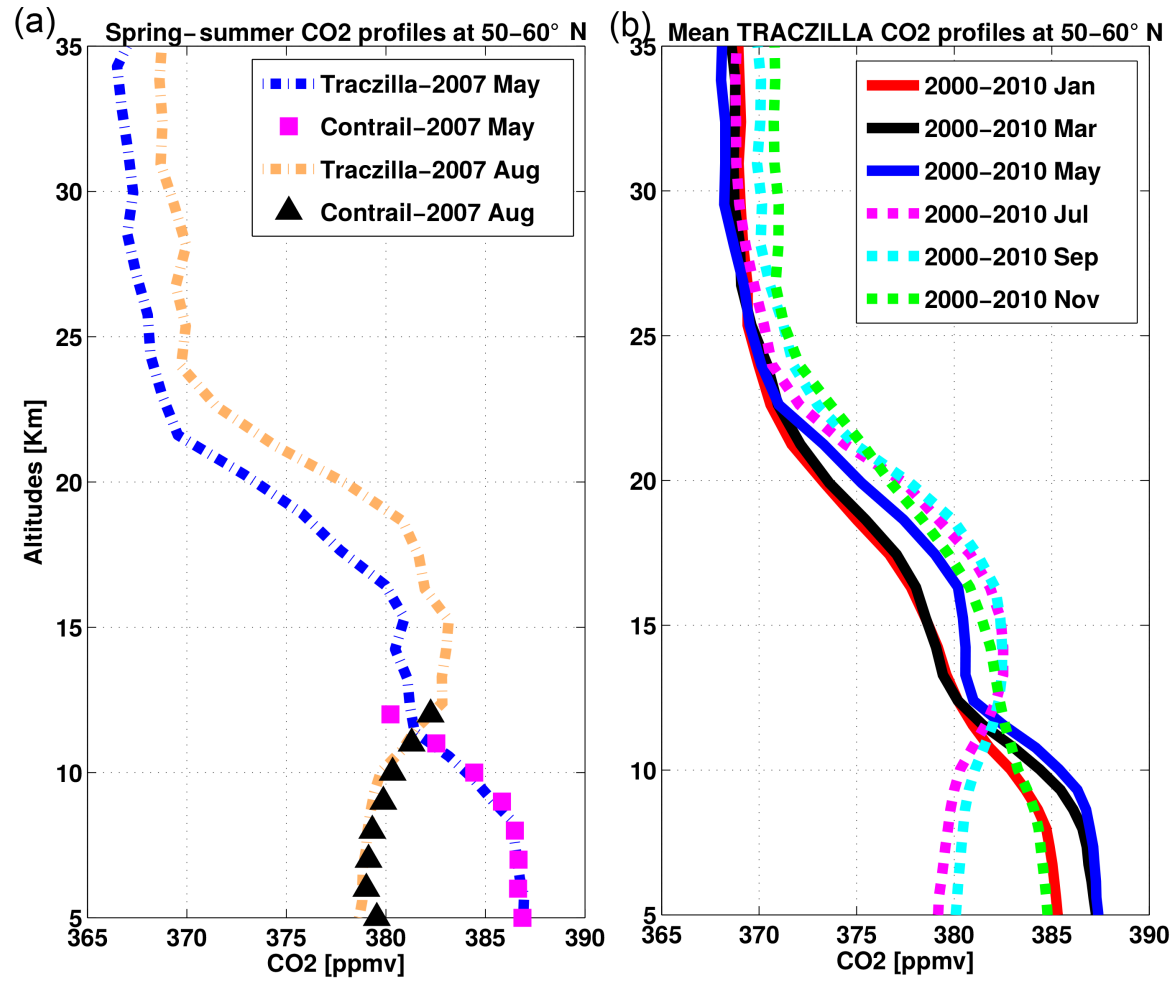

Figure 7. (a) Reconstructed vertical profiles of the mean $\mathrm{CO}_{2}$ compared with CONTRAIL measurements for 2007 at $50-60^{\circ} \mathrm{N}$. Dotted and dashed lines show vertical profiles of $\mathrm{CO}_{2}$ from TRACZILLA (blue: May, orange: August). Symbols show in situ aircraft measurements from the CONTRAIL campaign (magenta square: May, black triangle: August). (b) Averaged monthly profiles of the reconstructed $\mathrm{CO}_{2}$ over the period 2000-2010 after removal of the mean $\mathrm{CO}_{2}$ trend at each level and centred on 2007. Red is January, black is March, blue is May, magenta is July, cyan is September, and green is November.

ing that the contributing trajectories are independent samples. The standard error is performed for each month over 2000-2010. As an illustration, the standard error is then averaged over 11 years (Fig. 6c). The estimated $\mathrm{CO}_{2}$ uncertainties reveal smaller values for the trajectories starting in the troposphere than the trajectories starting in the stratosphere, which have a longer transit time of several years to reach the lower boundary condition where the $\mathrm{CO}_{2}$ value is assigned. As expected, the uncertainty roughly scales with the transit time of the trajectories from the upper troposphere to the stratosphere. The maximum uncertainty reaches $1 \mathrm{ppmv}$ in the stratospheric polar regions where the mean age of the air reaches a maximum during winter and sampling is lowest. Note that the mean error of CarbonTracker on the initialization values should be added to this uncertainty from the spread of the trajectories.

\subsection{Spring-summer vertical profiles}

In this section, monthly averaged $\mathrm{CO}_{2}$ profiles are investigated to better describe the changes in the $\mathrm{CO}_{2}$ vertical structure within the upper troposphere and stratosphere.

The spring-summer reconstructed vertical profiles of $\mathrm{CO}_{2}$ are compared with those from the CONTRAIL aircraft mea- surements for the year 2007 in the $50-60^{\circ} \mathrm{N}$ latitude range (Fig. 7a). Good agreement is obtained, including for the inversion of the $\mathrm{CO}_{2}$ vertical profile during August in the lower stratosphere. The monthly mean $\mathrm{CO}_{2}$ vertical profiles, calculated by backward trajectories, exhibit a complex vertical structure with gradient layers interspersed with no gradient layers.

The annual structure of the profile is made apparent in Fig. $7 \mathrm{~b}$, where we show averaged monthly profiles over the period 2000-2010 after removing the mean $\mathrm{CO}_{2}$ trend at each level. Starting from January, the increase in $\mathrm{CO}_{2}$ in the troposphere penetrates upward in the stratosphere over the limited vertical range of the extratropical transition layer (Hegglin et al., 2010; Gettelman et al., 2011), which is over 2 to $3 \mathrm{~km}$ above the tropopause, as is visible in the March profile. Between March and May, another process occurs, which injects young air rich in $\mathrm{CO}_{2}$ above $13 \mathrm{~km}$. This can only be due to a tropical intrusion promoted by the weakening of the tropical barrier at the end of the winter. The profile suggests (i) that the intrusion is deep from 13 to about $23 \mathrm{~km}$, (ii) that the well-mixed layer between 13 and $16 \mathrm{~km}$ is influenced by the well-mixed tropical tropospheric profile at such altitudes, and (iii) that the mixing layer between 16 and 
$23 \mathrm{~km}$ is also induced by the tropical lower stratosphere vertical gradient. The mixing layer persists with the same slope during the whole summer, and the bottom of the intrusion corresponds to the maximum of $\mathrm{CO}_{2}$ when the inversion is at its maximum. During autumn, when the subtropical barrier is re-established, the gradient weakens, the residual well-mixed layer disappears, and the profile returns to the fairly uniform slope of January.

\section{Conclusions}

Our study provides a monthly zonal mean distribution of $\mathrm{CO}_{2}$ spanning the upper troposphere and the stratosphere over the time period 2000-2010, established from observations and the state-of-the-art reanalysis ERA-Interim. The zonal mean distribution of $\mathrm{CO}_{2}$ is a unique data set of a critical trace gas that has a variety of uses for validating the representation of upper tropospheric and stratospheric tracer distributions in chemical transport models and chemical climate models, in particular regarding the summer inversion of the $\mathrm{CO}_{2}$ profile in the Northern Hemisphere. This $\mathrm{CO}_{2}$ product is also intended for satellite validation in the upper troposphere and the stratosphere. It is used as a preliminary process before (a prior) for inversion modelling and to analyse features of the stratospheric-tropospheric exchange as well as the stratospheric circulation and its variability. The reconstructed $\mathrm{CO}_{2}$ product contains zonal mean, monthly mean mixing ratios in 77 latitude bins from $90^{\circ} \mathrm{S}$ to $90^{\circ} \mathrm{N}$, and 36 vertical levels from 5 to $42 \mathrm{~km}$. This reconstructed monthly zonal mean $\mathrm{CO}_{2}$ exhibits a remarkable agreement with $\mathrm{CON}$ TRAIL data, SOLVE, and in situ balloon measurements.

The comparison with SOLVE shows that a Lagrangiandiffusive model is able to reproduce the mean value and the number of small-scale fluctuations that are recorded by in situ measurements along flight tracks in the lower stratosphere. This reconstruction suggests that the distribution of long-lived tracers, such as $\mathrm{CO}_{2}$, can be fully explained by the properties of transport, as resolved by meteorological analysis or reanalysis and a simple representation of sub-grid-scale effects as a diffusion.

In the northern hemispheric troposphere, the monthly mean $\mathrm{CO}_{2}$ is dominated by biospheric activity and displays a strong seasonal cycle, which is vertically and horizontally propagated to the tropopause and above in the lowermost extratropical stratosphere, on the one hand, and to the tropics, on the other hand, where it reaches the tropopause and enters the stratospheric Brewer-Dobson circulation. In regions of high horizontal mixing such as the mid-latitudes, $\mathrm{CO}_{2}$ tends to be uniformly mixed at isentropic surfaces and its meridional gradients are enhanced near transport barriers such as the subtropical jet during winter.
Transport of $\mathrm{CO}_{2}$ into the northern extratropical stratosphere above the lowermost stratosphere is due to the export of tropical air. The long circuit of $\mathrm{CO}_{2}$ from the extratropics to the tropics in the troposphere and then back to the extratropics in the stratosphere induces a time lag of 4-6 months such that the tropospheric and stratospheric variability are almost opposite at mid-latitudes. The result is the production of an inverted vertical $\mathrm{CO}_{2}$ profile during summer. In the mid- and upper stratosphere, we found that as the tropospheric seasonal cycle is transported into the stratosphere through the tropical pipe, its amplitude is smoothed out because of the combined effect of the upwelling branch of the $\mathrm{BDC}$ and quasi-horizontal mixing. A more confined tropical pipe is found in the tropical band during winter and spring than during summer and autumn.

Data availability. The reconstructed $\mathrm{CO}_{2}$ product will be published online at http://www.earth-system-science-data.net/ and made publicly available. The other data used in the manuscript are described in the manuscript and here: World Data Center for Greenhouse gases datasets are available at http://ds.data.jma.go.jp/gmd/wdcgg/, SOLVE datasets are from NASA (Daube et al., 2002) and can be download from http://espoarchive.nasa.gov/archive, CarbonTracker datasets are available at ftp://aftp.cmdl.noaa.gov/products/carbontracker/co2/ CT2016/molefractions/co2_components/, and balloon $\mathrm{CO}_{2}$ profiles are from Engel et al. (2009) and Ray et al. (2014). These data are not publicly available but can be obtained by contacting Andreas Engel (an.engel@iau.uni-franfurt.de) or Eric Ray (eric.ray@noaa.gov). CONTRAIL $\mathrm{CO}_{2}$ datasets are not publicly available but can be obtained by contacting Yousuke SAWA (ysawa@mri-jma.go.jp).

Competing interests. The authors declare that they have no conflict of interest.

Acknowledgements. We particularly thank Y. Sawa, H. Matsueda, and $\mathrm{T}$. Machida for providing $\mathrm{CO}_{2}$ measurements from $\mathrm{CON}-$ TRAIL, the ECWMF for providing reanalysis data, WDCGG (http://ds.data.jma.go.jp/gmd/wdegg/) and its contributors for providing the ground station $\mathrm{CO}_{2}$ data from 1989 to 1999 , and the CarbonTracker team for providing the $\mathrm{CO}_{2}$ data from 2000 to 2010. We thank Harald Bönisch and Alain Chédin for comments and helpful discussions. We acknowledge support from the EU 7th Framework Programme under grant 603557 (StratoClim). M. Diallo was mainly supported by a postdoctoral grant from the ExCirEs Project (CGL2011-24826) funded by the Government of Spain. Further thanks are due to the CICLAD cluster at the Institut Pierre Simon Laplace in Paris, on which most parts of this work were carried out. The TRACZILLA model $\mathrm{CO}_{2}$ data set may be requested from the corresponding author (mdiallo@1md.ens.fr/m.diallo@fz-juelich.de) before made publicly available to the scientific community on Earth System Science Data (ESSD). Finally, we thank all reviewers. 
Edited by G. Stiller.

Reviewed by M. Dameris, P. Hoor, and two anonymous referees

\section{References}

Abalos, M., Legras, B., Ploeger, F., and Randel, W. J.: Evaluating the advective Brewer-Dobson circulation in three reanalyses for the period 1979-2012, J. Geophys. Res. Atmos., 120, 75347554, doi:10.1002/2015JD023182, 2015.

Andrews, A. E., Boering, K. A., Daube, B. C., Wofsy, S. C., Hintsa, E. J., Weinstock, E. M., and Bui, T. P.: Mean age of stratospheric air derived from in situ observations of $\mathrm{CO}_{2}, \mathrm{CH}_{4}$ and $\mathrm{N}_{2} \mathrm{O}$, J. Geophys. Res., 106, 32 295-32 314, doi:10.1029/2001JD000465, 1999.

Andrews, A. E., Boering, K. A., Wofsy, S. C., Daube, B. C., Jones, D. B., Alex, S., Loewenstein, M., Podolske, J. R., and Strahan, S. E.: Empirical age spectra for the lower tropical stratosphere from in situ observations of $\mathrm{CO}_{2}$ : Quantitative evidence for a sub-tropical barrier to horizontal transport, J. Geophys. Res., 106, 32295-32314, doi:10.1029/2001JD000465, $2001 \mathrm{a}$.

Andrews, A. E., Boering, K. A., Daube, B. C., Wofsy, S. C., Loewenstein, M., Jost, H., Podolske, J. R., Webster, C. R., Herman, R. L., C., S. D., Flesch, G. J., Moyer, E. J., Elkins, J. W., Dutton, G. S., Hurst, D. F., Moore, F. L., Ray, E. A., Romashkin, P. A., and Strahan, S. E.: Mean age of stratospheric air derived from in situ observations of $\mathrm{CO}_{2}$ :Implications for stratospheric transport, J. Geophys. Res., 104, 26581-26596, doi:10.1029/1999JD900150, 2001b.

Andrews, D. G., Holton, J. R., and Leovy, C. B.: Middle Atmosphere Dynamics, International Geophysics Series, Academic Press, San Diego, USA, 40, 1987.

Bannister, R. N., O’Neil, A., Gregory, A. R., and Nissen, K. M.: The role of the south-east Asian monsoon and other seasonal features in creating the "tape-recorder"signal in the Unified Model, Q. J. R. Meteorol. Soc., 130, 1531-1554, doi:10.1256/qj.03.106, 2004.

Bergman, J. W., Jensen, E. J., Pfister, L., and Yang, Q.: Seasonal Differences of Vertical-Transport Efficiency in the Tropical Tropopause Layer: On the Interplay between Tropical Deep Convection, Large-Scale Vertical Ascent, and Horizontal Circulations, J. Geophys. Res., 117, D05302, doi:10.1029/2011JD016992, 2012.

Bernath, P. F., McElroy, C. T., Abrams, M. C., Boone, C. D., Butler, M., Camy-Peyret, C., Carleer, M., Clerbaux, C., Coheur, P.-F., Colin, R., DeCola, P., DeMaziere, M., Drummond, J. R., Dufour, D., Evans, W. F. J., Fast, H., Fussen, D., Gilbert, K., Jennings, D. E., Llewellyn, E. J., Lowe, R. P., Mahieu, E., McConnell, J. C., McHugh, M., McLeod, S. D., Michaud, R., Midwinter, C., Nassar, R., Nichitiu, F., Nowlan, C., Rinsland, C. P., Rochon, Y. J., Rowlands, N., Semeniuk, K., Simon, P., Skelton, R., Sloan, J. J., Soucy, M.-A., Strong, K., Tremblay, P., Turnbull, D., Walker, K. A., Walkty, I., Wardle, D. A., Wehrle, V., Zander, R., and Zou, J.: Atmospheric Chemistry Experiment (ACE): Mission overview, J. Geophys. Res., 32, L15S01, doi:10.1029/2005GL022386, 2005.

Boering, K. A., Wofsy, S. C., Daube, B. C., Schneider, H. R., Loewenstein, M., Podolske, J. R., and Conway, T. J.: Stratospheric mean ages and transport rates from observations of carbon dioxide and nitrous oxide, Science, 274, 1340-1343, doi:10.1126/science.274.5291.1340, 1996.

Bönisch, H. B., Hoor, P., Gurk, C., Feng, W., Chipperfield, M., Engel, A., and Bregman, B.: Model evaluation of $\mathrm{CO}_{2}$ and $\mathrm{SF}_{6}$ in the extratropical UT/LS region, J. Geophys. Res., 113, D06101, doi:10.1029/2007JD008829, 2008.

Bönisch, H. B., Engel, A., Curtius, H., Birner, T., and Hoor, P.: Quantifying transport into the lowersmost stratosphere using simultaneous in-situ measurements of $\mathrm{SF}_{6}$ and $\mathrm{CO}_{2}$, Atmos. Chem. Phys., 9, 5905-5919, doi:10.5194/acp-9-5905-2009, 2009.

Bönisch, H. B., Engel, A., Birner, T., Hoor, P., Tarasick, D. W., and Ray, E. A.: On the structural changes in the Brewer-Dobson circulation after 2000, Atmos. Chem. Phys., 11, 3937-3948, doi:10.5194/acp-11-3937-2011, 2011.

Boucher, O., Friedlingstein, P., Collins, B., and Keith P Shine, K. P.: The indirect global warming potential and global temperature change potential due to methane oxidation, Environ. Res. Lett., 4, 044007, doi:10.1088/1748-9326/4/4/044007, 2009.

Bowman, M., Rozanov, V. V., and Burrows, J. P.: A near-infrared optimized DOAS method for the fast global retrieval of atmospheric $\mathrm{CH}_{4}, \mathrm{CO}, \mathrm{CO}_{2}, \mathrm{H}_{2} \mathrm{O}$, and $\mathrm{N} 2 \mathrm{O}$ total column amounts from SCIAMACHY Envisat-1 nadir radiances, J. Geophys. Res., 105, 15231-15245, doi:10.1029/2000JD900191, 2000.

Butchart, N., Cionni, I., Eyring, V., Shepherd, T. G., Waugh, D. W., Akiyoshi, H., Austin, J., Brã̃1/4hl, C., Chipperfield, M. P., Cordero, E., Dameris, M., Deckert, R., Dhomse, S., Frith, S. M., Garcia, R. R., Gettelman, A., Giorgetta, M. A., Kinnison, D. E., Li, F., Mancini, E., McLandress, C., Pawson, S., Pitari, G., Plummer, D. A., Rozanov, E., Sassi, F., Scinocca, J. F., Shibata, K., Steil, B., and Tian, W.: ChemistryClimate Model simulations of twenty-first century stratospheric climate and circulation changes, J. Climate, 23, 5349-5374, doi:10.1175/2010JCLI3404.1, 2010.

Chedin, A., Hollingsworth, A., Scott, N. A., Serrar, S., Crevoisier, C., and Armante, R.: Annual and seasonal variations of atmospheric $\mathrm{CO}_{2}, \mathrm{~N}_{2} \mathrm{O}$ and $\mathrm{CO}$ concentrations retrieved from NOAA/TOVS satellite observations, Geophys. Res. Lett., 29, 1269, doi:10.1029/2001GL014082, 2002.

Chedin, A., Saunders, R., Hollingsworth, A., Scott, N., Matricardi, M., Etcheto, J., Clerbaux, C., Armante, R., and Crevoisier, C.: The feasibility of monitoring $\mathrm{CO}_{2}$ from highresolution infrared sounders, J. Geophys. Res., 108, 4064, doi:10.1029/2001JD001443, 2003a.

Chedin, A., Serrar, S., Scott, N. A., Crevoisier, C., and Armante, R.: First global measurement of midtropospheric $\mathrm{CO}_{2}$ from NOAA polar satellites: Tropical zone, J. Geophys. Res., 108, 4581, doi:10.1029/2003JD003439, 2003b.

Daube, B. C. J., Boering, K. A., Andrews, A. E., and Wofsy, S. C.: A High-Precision Fast-Response Airborne $\mathrm{CO}_{2}$ Analyzer for In Situ Sampling from the Surface to the Middle Stratosphere, J. Atmos Oceanic Technol., 19, 1532-1543, doi:10.1175/15200426(2002)019<1532:AHPFRA>2.0.CO;2, 2002.

Dee, D. P., Uppala, S. M., Simmons, A. J., Berrisford, P., Poli, P., Kobayashi, S., Andrae, U., Balmaseda, M. A., Balsamo, G., Bauer, P., Bechtold, P., Beljaars, A. C. M., van de Berg, L., Bidlot, J., Bormann, N., Delsol, C., Dragani, R., Fuentes, M., Geer, A. J., Haimberger, L., Healy, S. B., Hersbach, H., Hólm, E. V., Isaksen, L., Kållberg, P., Köhler, M., Matricardi, M., McNally, 
A. P., Monge-Sanz, B. M., Morcrette, J.-J., Park, B.-K., Peubey, C., de Rosnay, P., Tavolato, C., Thépaut, J.-N., and Vitart, F.: The ERA-Interim reanalysis: configuration and performance of the data assimilation system, Q. J. R. Meteorol. Soc., 137, 553-597, doi:10.1002/qj.828, 2011.

Dethof, A., O'Neill, A., and Slingo, J.: Quantification of the isentropic mass transport across the dynamical tropopause, J. Geophys. Res., 105, 12279-12293, doi:10.1029/2000JD900127, 2000.

Diallo, M., Legras, B., and Chédin, A.: Age of stratospheric air in the ERA-Interim, Atmos. Chem. Phys., 12, 12133-12154, doi:10.5194/acp-12-12133-2012, 2012.

Eluszkiewicz, J., Hemler, R. S., Mahlman, J. D., Bruhwiler, L., and Takacs, L. L.: Sensitivity of Age-of-Air Calculations to the Choice of Advection Scheme, J. Atmos. Sci., 57, 3185-3201, doi:10.1175/1520-0469(2000)057<3185:SOAOAC>2.0.CO;2, 2000.

Engel, A., Bönisch, H., Brunner, D., Fischer, H., Franke, H., Günther, G., Gurk, C., Hegglin, M., Hoor, P., Königstedt, R., Krebsbach, M., Maser, R., Parchatka, U., Peter, T., Schell, D., Schiller, C., Schmidt, U., Spelten, N., Szabo, T., Weers, U., Wernli, H., Wetter, T., and Wirth, V.: Highly resolved observations of trace gases in the lowermost stratosphere and upper troposphere from the Spurt project: an overview, Atmos. Chem. Phys., 6, 283-301, doi:10.5194/acp-6-283-2006, 2006.

Engel, A., Möbius, T., Bönisch, H., Schmidt, U., Heinz, R., Levin, I., Atlas, E., Aoki, S., Nakazawa, T., Sugawara, S., Moore, F., Hurst, D., Elkins, J., Schauffler, S., Andrews, A., and Boering, K.: Age of stratospheric air unchanged within uncertainties over the past 30 years, Nat. Geosci., 2, 28-31, doi:10.1038/ngeo388, 2009.

Forster, P. M., Ramaswamy, V., Artaxo, P., Berntsen, T., Betts, R., Fahey, D. W., Haywood, J., Lean, J., Lowe, D. C., Myhre, G., Nganga, J., Prinn, R., Raga, G., Schulz, M., and Van Dorland, $\mathrm{R}$.: Changes in atmospheric constituents and in radiative forcing Climate Change 2007: The Physical Science Basis. Contribution of Working Group I to the Fourth Assessment Report of the Intergovernmental Panel on Climate Change, edited by: Solomon, S., Qin, D., Manning, M., Chen, Z., Marquis, M., Averyt, K. B., Tignor, M., and Miller, H. L., Cambridge University Press, Cambridge, United Kingdom and New York, NY, USA, 129-234, 2007.

Forster, P. M. D. F. and Shine, K. P.: Radiative forcing and temperature trends from stratospheric ozone changes, Geophys. Res. Lett., 102, 10841-10855, doi:10.1029/96JD03510, 1997.

Foucher, P. Y., Chedin, A., Armante, R., Boone, C., Crevoisier, C., and Bernath, P.: Technical Note: Feasibility of $\mathrm{CO}_{2}$ profile retrieval from limb viewing solar occultation made by the ACE-FTS instrument, Atmos. Chem. Phys., 9, 2873-2890, doi:10.5194/acp-9-2873-2009, 2009.

Foucher, P. Y., Chedin, A., Armante, R., Boone, C., Crevoisier, C., and Bernath, P.: Carbon dioxide atmopheric vertical profiles retrieved from space observation using ACE-FTS solar occultation instrument, Atmos. Chem. Phys., 11, 2455-2470, doi:10.5194/acp-11-2455-2011, 2011.

Frankenberg, C., Pollock, R., Lee, R. A. M., Rosenberg, R., Blavier, J.-F., Crisp, D., O’Dell, C. W., Osterman, G. B., Roehl, C., Wennberg, P. O., and Wunch, D.: The Orbiting Carbon Observatory (OCO-2): spectrometer performance evaluation using pre- launch direct sun measurements, Atmos. Meas. Tech., 8, 301313, doi:10.5194/amt-8-301-2015, 2015.

Garny, H., Dameris, M., Randel, W., Bodeker, G. E., and Deckert, R.: Dynamically forced increase of tropical upwelling in the lower stratosphere, J. Atmos. Sci., 68, 1214-1233, doi:10.1175/2011JAS3701.1, 2011.

Gettelman, A., Hoor, P., Pan, L. L., Randel, W. J., Hegglin, M. I., and Birner, T.: The extratropical upper troposphere and lower stratosphere, Rev. Geophys., 49, RG3003, doi:10.1029/2011RG000355, 2011.

Gurk, Ch., Fischer, H., Hoor, P., Lawrence, M. G., Lelieveld, J., and Wernli, H.: Airborne in-situ measurements of vertical, seasonal and latitudinal distributions of carbon dioxide over Europe, Atmos. Chem. Phys., 8, 6395-6403, doi:10.5194/acp-8-6395-2008, 2008.

Hammerling, D. M., Michalak, A. M., O'Dell, C., and Kawa, S. R.: Global $\mathrm{CO}_{2}$ distributions over land from the Greenhouse Gases Observing Satellite (GOSAT), Geophys. Res. Lett., 39, L08804, doi:10.1029/2012GL051203, 2012.

Haynes, P. H. and Shuckburgh, E.: Effective diffusivity as a diagnostic of atmospheric transport 1 . Stratosphere, J. Geophys. Res., 105, 22777-22794, doi:10.1029/2000JD900093, 2000a.

Haynes, P. H. and Shuckburgh, E.: Effective diffusivity as a diagnostic of atmospheric transport, 2. Troposphere and lower stratosphere, J. Geophys. Res., 105, 22795-22810, doi:10.1029/2000JD900092, 2000b.

Haynes, W. M. and Lide, D. R., (Eds.): CRC Handbook of Chemistry and Physics: A Ready-Reference Book of Chemical and Physical Data, CRC Press, Boca Raton, Fla., 93rd Edn., 20122013, oCLC: 796257574, 2012.

Hegglin, M. I., Brunner, D., Peter, T., Staehelin, J., Wirth, V., Hoor, P., and Fischer, H.: Determination of eddy diffusivity in the lowermost stratosphere, Geophys. Res. Lett., 32, L13812, doi:10.1029/2005GL022495, 2005.

Hegglin, M. I., Boone, C. D., Manney, G. L., Shepherd, T. G., Walker, K. A., Bernath, P. F., Daffer, W. H., Hoor, P., and Schiller, C.: Validation of ACE-FTS satellite data in the upper troposphere/lower stratosphere (UTLS) using non-coincident measurements, Atmos. Chem. Phys., 8, 1483-1499, doi:10.5194/acp8-1483-2008, 2008.

Hegglin, M. I., Gettelman, A., Hoor, P., Krichevsky, R., Manney, G. L., Pan, L. L., Son, S.-W., Stiller, G., Tilmes, S., Walker, K. A., Eyring, V., Shepherd, T. G., Waugh, D., Akiyoshi, H., nel, J. A. A., Austin, J., Baumgaertner, A., Bekki, S., Braesicke, P., Brúhl, C., Butchart, N., Chipperfield, M., Dameris, M., Dhomse, S., Frith, S., Garny, H., Hardiman, S. C., Jöckel, P., Kinnison, D. E., Lamarque, J. F., Mancini, E., Michou, M., Morgenstern, O., Nakamura, T., Olivié, D., Pawson, S., Pitari, G., Plummer, D. A., Pyle, J. A., Rozanov, E., Scinocca, J. F., Shibata, K., Smale, D., Teyssédre, H., Tian, W., and Yamashia, Y.: Multimodel assessment of the upper troposphere and lower stratosphere: Extratropics, J. Geophys. Res., 115, D00M09, doi:10.1029/2010JD013884, 2010.

Holton, J. R., Haynes, P. H., McIntyre, M. E., Douglass, A. R., Rood, R. B., and Pfister, L.: Stratosphere-troposphere exchange, Rev. Geophys., 33, 403-440, doi:10.1029/95RG02097, 1995.

Hoor, P., Gurk, C., Brunner, D., Hegglin, M. I., Wernli, H., and Fischer, H.: Seasonality and extent of extratropical TST derived 
from in-situ CO measurements during SPURT, Atmos. Chem. Phys., 4, 1427-1442, doi:10.5194/acp-4-1427-2004, 2004.

Hoor, P., Fischer, H., and Lelieveld, J.: Tropical and extratropical tropospheric air in the lowermost stratosphere over Europe: ACO-based budget, Geophys. Res. Lett., 32, L13812, doi:10.1029/2005GL022495, 2005.

Hoor, P., Wernli, H., Hegglin, M. I., and Bönisch, H.: Transport timescales and tracer properties in the extratropical UTLS, Atmos. Chem. Phys., 10, 7929-7944, doi:10.5194/acp-10-79292010, 2010.

Huijnen, V., Williams, J., van Weele, M., van Noije, T., Krol, M., Dentener, F., Segers, A., Houweling, S., Peters, W., de Laat, J., Boersma, F., Bergamaschi, P., van Velthoven, P., Le Sager, P., Eskes, H., Alkemade, F., Scheele, R., Nédélec, P., and Pätz, H.-W.: The global chemistry transport model TM5: description and evaluation of the tropospheric chemistry version 3.0, Geosci. Model Dev., 3, 445-473, doi:10.5194/gmd-3-445-2010, 2010.

James, R. and Legras, B.: Mixing processes and exchanges in the tropical and the subtropical UT/LS, Atmos. Chem. Phys., 9, 2538, doi:10.5194/acp-9-25-2009, 2009.

Konopka, P., Grooß, J.-U., Günther, G., McKenna, D. S., Müller, R., Elkins, J., Fahey, D., and Popp, P.: Weak impact of mixing on chlorine deactivation during SOLVE/THESEO 2000: Lagrangian modeling (CLaMS) versus ER-2 in situ observations, J. Geophys. Res., 108, 8324, doi:10.1029/2001JD000876, 2003.

Lacis, A. A., Wuebbles, D. J., and Logan, J. A.: Radiative forcing of climate by changes in the vertical distribution of ozone, J. Geophys. Res., 95, 9971-9981, doi:10.1029/JD095iD07p09971, 1990.

Legras, B., Pisso, I., Berthet, G., and Lefèvre, F.: Variability of the Lagrangian turbulent diffusion in the lower stratosphere, Atmos. Chem. Phys., 5, 1605-1622, doi:10.5194/acp-5-1605-2005, 2005.

Li, F., Waugh, D. W., Douglass, A. R., Newman, P. A., Pawson, S., Stolarski, R. S., Strahan, S. E., and Nielsen, J. E.: Seasonal variations of stratospheric age spectra in the Goddard Earth Observing System Chemistry Climate Model (GEOSCCM), J. Geophys. Res., 117, 134, D05134, doi:10.1029/2011JD016877, 2012.

Li, S. and Waugh, D. W.: Sensitivity of mean age and long-lived tracers to transport parameters in a twodimensional model, J. Geophys. Res., 104, 30559-30569, doi:10.1029/1999JD900913, 1999.

Liu, J., Bowman, K. W., and Henze, D. K.: Source-receptor relationships of column-average $\mathrm{CO} 2$ and implications for the impact of observations on flux inversions, J. Geophys. Res., 120, 5214-5236, doi:10.1002/2014JD22914, 2014.

Machida, T., Kita, K., Kondo, Y., Blake, D., Kawakami, S., Inoue, G., and Ogawa, T.: Vertical and Meridional Distributions of the Atmospheric $\mathrm{CO}_{2}$ Mixing Ratio between Northern Midlatitudes and Southern Subtropics, J. Geophys. Res., 108, D38401, doi:10.1029/2001JD000910, 2002.

Machida, T., Matsueda, H., Sawa, Y., Nakagawa, Y., Hirotani, K., Kondo, N., Goto, K., Nakazawa, T., Ishikawa, K., and Ogawa, T.: Worldwide Measurements of Atmospheric $\mathrm{CO}_{2}$ and Other Trace Gas Species Using Commercial Airlines, J. Atmos. Ocean. Technol., 25, 1744-1754, doi:10.1175/2008JTECHA1082.1, 2008.

Miyazaki, K., Machida, T., Patra, P. K., Sawa, Y., Matsueda, H., and Nakazawa, T.: Formation mechanisms of latitudinal $\mathrm{CO}_{2}$ gradients in the upper troposphere over the subtropics and trop- ics, J. Geophys. Res., 114, D03306, doi:10.1029/2008JD010545, 2009.

Nakamura, N., Miyashita, K., Aoki, S., and Tanaka, M.: Temporal and spatial variation of upper tropospheric and lower stratospheric carbon dioxide, Tellus B, 43, 106-117, 1991.

Olsen, S. C. and Randerson, J. T.: Differences between surface and column atmospheric $\mathrm{CO}_{2}$ and implications for carbon cycle research, J. Geophys. Res., 109, D02301, doi:10.1029/2003JD003968, 2004.

Pan, L., Honomichl, S. B., Kinnison, D. E., Abalos, M., Randel, W. J., Bergman, J. W., and Bian, J.: Transport of Chemical Tracers from the Boundary Layer to Stratosphere Associated with the Dynamics of the Asian Summer Monsoon, J. Geophys. Res., 121, 2169-8996, doi:10.1002/2016JD025616, 2016.

Pan, L. L., Konopka, P., and Browell, E. V.: Observations and model simulations of mixing near the extratropical tropopaus, J. Geophys. Res., 111, D05106, doi:10.1029/2005JD006480, 2006.

Park, M., Randel, W. J., Gettelman, A., Massie, S. T., and Jiang, J. H.: Transport above the Asian summer monsoon anticyclone inferred from aura microwave limb sounder tracers, J. Geophys. Res., 112, D16309, doi:10.1029/2006JD008294, 2007b.

Park, M., Randel, W. J., Emmons, L. K., Bernath, P. F., Walker, K. A., and Boone, C. D.: Chemical isolation in the Asian monsoon anticyclone observed in Atmospheric Chemistry Experiment (ACE-FTS) data, Atmos. Chem. Phys., 8, 757-764, doi:10.5194/acp-8-757-2008, 2008.

Park, M., Randel, W. J., Emmons, L. K., and Livesey, N. J.: Transport pathways of carbon monoxide in the Asian summer monsoon diagnosed from Model of Ozone and Related Tracers (MOZART), J. Geophys. Res., 114, D08303, doi:10.1029/2008JD010621, 2009.

Park, S., Atlas, E. L., Jiménez, R., Daube, B. C., Gottlieb, E. W., Nan, J., Jones, D. B. A., Pfister, L., Conway, T. J., Bui, T. P., Gao, R.-S., and Wofsy, S. C.: Vertical transport rates and concentrations of $\mathrm{OH}$ and $\mathrm{Cl}$ radicals in the Tropical Tropopause Layer from observations of $\mathrm{CO}_{2}$ and halocarbons: implications for distributions of long- and short-lived chemical species, Atmos. Chem. Phys., 10, 6669-6684, doi:10.5194/acp-10-66692010, 2010.

Peters, W., Jacobson, A. R., Sweeney, C., Andrews, A. E., Conway, T. J., Masarie, K., Miller, J. B., Bruhwiler, L. M. P., Petron, G., Hirsch, A. I., Worthy, D. E. J., van der Werf, G. R., Randerson, J. T., Wennberg, P. O., Krol, M. C., and Tans, P. P.: An atmospheric perspective on North American carbon dioxide exchange: CarbonTracker, P. Natl. Acad. Sci. USA, 104, 1892518930, 2007.

Pisso, I. and Legras, B.: Turbulent vertical diffusivity in the sub-tropical stratosphere, Atmos. Chem. Phys., 8, 697-707, doi:10.5194/acp-8-697-2008, 2008.

Pommrich, R., Müller, R., Grooß, J.-U., Konopka, P., Ploeger, F., B. Vogel, M. T., Hoppe, C. M., Günther, G., Spelten, N., Hoffmann, L., Pumphrey, H.-C., S. Viciani, F. D., Volk, C. M., Hoor, P., Schlager, H., and Riese, M.: Tropical troposphere to stratosphere transport of carbon monoxide and long-lived trace species in the Chemical Lagrangian Model of the Stratosphere (CLaMS), Geosci. Model Dev., 7, 2895-2916, doi:10.5194/gmd-7-28952014, 2014. 
Randel, W. J., Park, M., Wu, F., and Livesey, N.: Asian monsoon transport of pollution to the stratosphere, Science, 328, 611-613, doi:10.1126/science.1182274, 2010.

Ray, E. A., Moore, F. L., Rosenlof, K. H., Davis, S. M., Sweeney, C., Bönisch, H., Engel, A., Sugawara, S., Nakazawa, T., and Aoki, S.: Improving stratospheric transport trend analysis based on SF6 and $\mathrm{CO}_{2}$ measurements, J. Geophys. Res., 119, 14110-14128, doi:10.1002/2014JD021802, 2014.

Riese, M., Ploeger, F., Rap, A., Vogel, B., Konopka, P., Dameris, M., and Forster, P.: Impact of uncertainties in atmospheric mixing on simulated UTLS composition and related radiative effects, J. Geophys. Res., 117, D16305, doi:10.1029/2012JD017751, 2012.

Salby, M. L. and Callaghan, P. F.: Interaction between the Brewer Dobson Circulation and the Hadley Circulation, J. Clim., 18, 4303-4316, doi:10.1175/JCLI3509.1, 2005.

Salby, M. L. and Callaghan, P. F.: Influence of the Brewer-Dobson circulation on stratosphere-troposphere exchange, J. Geophys. Res., 111, D21106, doi:10.1029/2006JD007051, 2006.

Sawa, Y., Machida, T., and Matsueda, H.: Seasonal variations of $\mathrm{CO}_{2}$ near the tropopause observation by commercial aircraft, J. Geophys. Res., 113, D23301, doi:10.1029/2008JD010568, 2008.

Sawa, Y., Machida, T., and Matsueda, H.: Aircraft observation of the seasonal variation in the transport of $\mathrm{CO}_{2}$ in the upper atmosphere, J. Geophys. Res., 117, D05305, doi:10.1029/98JD01143, 2012.

Scheele, M. P., Siegmund, P. C., and Velthoven, P. F. J.: Stratospheric age of air computed with trajectories based on various 3D-Var and 4D-Var data sets, Atmos. Chem. Phys., 5, 1-7, doi:10.5194/acp-5-1-2005, 2005.

Schuck, T. J., Brenninkmeijer, C. A. M., Slemr, F., Xueref-Remy, I., and Zahn, A.: Greenhouse gas analysis of air samples collected onboard the CARIBIC passenger aircraft, Atmos. Meas. Tech., 2, 449-464, doi:10.5194/amt-2-449-2009, 2009.
Shia, R.-L., Liang, M.-C., Miller, C. E., and Yung, Y. L.: $\mathrm{CO}_{2}$ in the upper troposphere: Influence of stratospheretroposphere exchange, Geophys. Res. Lett., 33, L14814, doi:10.1029/2006GL026141, 2006.

Sprung, D. and Zahn, A.: Acetone in the upper troposphere/lowermost stratosphere measured by the CARIBIC passenger aircraft: Distribution, seasonal cycle, and variability, J. Geophys. Res., 115, D16301, doi:10.1029/2009JD012099, 2010.

Stohl, A., Forster, C., Frank, A., Seibert, P., and Wotawa, G.: Technical note: The Lagrangian particle dispersion model FLEXPART version 6.2, Atmos. Chem. Phys., 5, 2461-2474, doi:10.5194/acp-5-2461-2005, 2005.

Strahan, S., Douglass, A., Nielsen, J. E., and Boering, K. A.: The $\mathrm{CO}_{2}$ seasonal cycle as a tracer of transport, J. Geophys. Res., 103, 13729-13741, doi:10.1029/98JD01143, 1998.

Strahan, S. E., Duncan, B. N., and Hoor, P.: Observationally derived transport diagnostics for the lowermost stratosphere and their application to the GMI chemistry and transport model, Atmos. Chem. Phys., 7, 2435-2445, doi:10.5194/acp-7-2435-2007, 2007.

Tans, P. P. and Keeling, R.: Trends in atmospheric carbon dioxide, NOAA-ERSL webpage, 2015.

Tissier, A.-S. and Legras, B.: Convective Sources of Trajectories Traversing the Tropical Tropopause Layer, Atmos. Chem. Phys., 16, 3383-3398, doi:10.5194/acp-16-3383-2016, 2016.

Waugh, D.: Atmospheric dynamics: The age of stratospheric air, Nat. Geosci., 2, 14-16, doi:10.1038/ngeo397, 2009.

Waugh, D. and Hall, T.: Age of stratospheric air: Theory, observations, and models, Rev. Geophys., 40, 1010, doi:10.1029/2000RG000101, 2002.

Worden, J., Noone, D., Galewsky, J., Bailey, A., Bowman, K., Brown, D., Hurley, J., Kulawik, S., Lee, J., and Strong, M.: Analysis based on data submitted by November 2014, except for the greenhouse gas species $\mathrm{CO}_{2}, \mathrm{CH}_{4}, \mathrm{~N}_{2} \mathrm{O}$, SF6 and halocarbons, for which the submission period ended in July 2014, WDCGG report, 130 pp., 2015. 